\title{
Measuring short distance dispersal of Alliaria petiolata and determining potential long distance dispersal mechanisms
}

\author{
Christopher A. Loebach ${ }^{\text {Corresp., }}{ }^{1}$, Roger C. Anderson ${ }^{1}$ \\ ${ }^{1}$ School of Biological Sciences, Illinois State University, Normal, Illinois, United States \\ Corresponding Author: Christopher A. Loebach \\ Email address: chris_loebach@yahoo.com
}

Introduction: Alliaria petiolata, an herbaceous plant, has invaded woodlands in North America. Its ecology has been thoroughly studied, but an overlooked aspect of its biology is seed dispersal distances and mechanisms. We measured seed dispersal distances in the field and tested if epizoochory is a potential mechanism for long-distance seed dispersal.

Methods: Dispersal distances were measured by placing seed traps in a sector design around three seed point sources, which consisted of 15 second-year plants transplanted within a $0.25 \mathrm{~m}$ radius circle. Traps were placed at intervals ranging from 0.25-3.25 $\mathrm{m}$ from the point source. Traps remained in the field until a majority of seeds were dispersed. Eight probability density functions were fitted to seed trap counts via maximum likelihood. Epizoochory was tested as a potential seed dispersal mechanism for $A$. petiolata through a combination of field and laboratory experiments. To test if small mammals transport A. petiolata seeds in their fur, experimental blocks were placed around dense A. petiolata patches. Each block contained a mammal inclusion treatment (MIT) and control. The MIT consisted of a wood-frame $(31 \times 61 \times 31 \mathrm{~cm})$ covered in wire mesh, except for the two $31 \times 31 \mathrm{~cm}$ ends, placed over a germination tray filled with potting soil. A pan filled with bait was placed in the center of the tray. The control frame $(11 \times 31 \times 61 \mathrm{~cm})$ was placed over a germination tray and completely covered in wire mesh to exclude animal activity. Treatments were in the field for peak seed dispersal. In March, trays were moved to a greenhouse and $A$. petiolata seedlings were counted and then compared between treatments. To determine if $A$. petiolata seeds attach to raccoon (Procyon lotor) and white-tailed deer (Odocoileus virginianus) fur, wet and dry seeds were dropped onto wet and dry fur. Furs were rotated 180 degrees and the seeds that remained attached were counted. To measure seed retention, seeds were dropped on furs and rotated as before. Then the furs were agitated for one hour. The seeds retained in the fur were counted.

Results: For the seed dispersal experiment, the 2Dt function provided the best fit and was the most biologically meaningful. It predicted that seed density rapidly declined with distance from the point source. Mean dispersal distance was $0.52 \mathrm{~m}$ and $95 \%$ of seeds dispersed within $1.14 \mathrm{~m}$. The epizoochory field experiment showed increased mammal activity and $A$. petiolata seedlings in germination trays of the MIT compared to control.Laboratory studies showed $3-26 \%$ of seeds were attached and retained by raccoon and deer fur. Retention significantly increased if either seed or fur were wet (57-98\%).

Discussion: Without animal seed vectors, most seeds fall within a short distance of the seed source; however, long distance dispersal may be accomplished by epizoochory. Our data are consistent with $A$. petiolata's widespread distribution and development of dense clusters of the species in invaded areas. 
1 Measuring short distance dispersal of Alliaria petiolata and determining potential long-distance

2 dispersal mechanisms.

3

4

5

6

7

8 Affiliation for Authors:

9 Illinois State University

10 School of Biological Sciences

11

12 Address for Authors:

13 School of Biological Sciences

14 Illinois State University

15 Normal IL, 61790-4120

16

17

18

19

20

21

22

23

24

25

26
Christopher A. Loebach ${ }^{1}$ and Roger C. Anderson ${ }^{1}$ 


\section{Abstract}

Introduction:Alliaria petiolata, an herbaceous plant, has invaded woodlands in North America. Its ecology has been thoroughly studied, but an overlooked aspect of its biology is seed dispersal distances and mechanisms. We measured seed dispersal distances in the field and tested if epizoochory is a potential mechanism for long-distance seed dispersal.

Methods:Dispersal distances were measured by placing seed traps in a sector design around three seed point sources, which consisted of 15 second-year plants transplanted within a $0.25 \mathrm{~m}$ radius circle. Traps were placed at intervals ranging from $0.25-3.25 \mathrm{~m}$ from the point source. Traps remained in the field until a majority of seeds were dispersed. Eight probability density functions were fitted to seed trap counts via maximum likelihood. Epizoochory was tested as a potential seed dispersal mechanism for $A$. petiolata through a combination of field and laboratory experiments. To test if small mammals transport $A$. petiolata seeds in their fur, experimental blocks were placed around dense $A$. petiolata patches. Each block contained a mammal inclusion treatment (MIT) and control. The MIT consisted of a wood-frame $(31 \times 61 \times 31 \mathrm{~cm})$ covered in wire mesh, except for the two $31 \times 31 \mathrm{~cm}$ ends, placed over a germination tray filled with potting soil. A pan filled with bait was placed in the center of the tray. The control frame $(11 \times 31 \times 61 \mathrm{~cm})$ was placed over a germination tray and completely covered in wire mesh to exclude animal activity. Treatments were in the field for peak seed dispersal. In March, trays were moved to a greenhouse and $A$. petiolata seedlings were counted and then compared between treatments. To determine if $A$. petiolata seeds attach to raccoon (Procyon lotor) and white-tailed deer (Odocoileus virginianus) fur, wet and dry seeds were dropped onto wet and dry fur. Furs were rotated 180 degrees and the seeds that remained attached were counted. To measure seed retention, seeds were dropped on furs and rotated as before. Then the furs were agitated for one hour. The seeds retained in the fur were counted.

Results:For the seed dispersal experiment, the 2Dt function provided the best fit and was the most biologically meaningful. It predicted that seed density rapidly declined with distance from the point source. Mean dispersal distance was $0.52 \mathrm{~m}$ and $95 \%$ of seeds dispersed within $1.14 \mathrm{~m}$. The epizoochory field experiment showed increased mammal activity and $A$. petiolata seedlings in germination trays of the MIT compared to control. Laboratory studies showed $3-26 \%$ of seeds were attached and retained by raccoon and deer fur. Retention significantly increased if either seed or fur were wet (57-98\%).

Discussion:Without animal seed vectors, most seeds fall within a short distance of the seed source; however, long distance dispersal may be accomplished by epizoochory. Our data are consistent with $A$. petiolata's widespread distribution and development of dense clusters of the species in invaded areas. 


\section{Introduction}

Alliaria petiolata, garlic mustard (Brassicaceae: Bieb. [Cavara \& Grande]), is an

herbaceous invasive species that has invaded woodlands in eastern North America (Anderson et al. 1996). Alliaria petiolata is native to Eurasia, occurring from England to Sweden to Turkestan, northwestern-Himalayas, India and Sri Lanka, and south to Italy and the Mediterranean basin (Tutin et al. 1964; Cavers et al. 1979). It also occurs outside of its native range in Australia (CAB International 2015, EDDMapS 2015). The species was first recorded in North America on Long Island, New York in 1868 where it was introduced by humans as a food plant (Nuzzo 1993, Roberts and Anderson 2001). Since that time, it has spread exponentially and currently occurs in 37 states that stretch from the New England area to the west coast and five Canadian providences (USDA Plant Database). It is classified as invasive in 20 U.S. states and in the five Canadian provinces (CAB International 2015, EDDMapS 2015). Alliaria petiolata has been extensively studied in an effort to understand its invasive ability and impact on native communities (Rodgers et al. 2008). To better understand $A$. petiolata invasive ability, studies have investigated the competition between $A$. petiolata and native plant species (Bauer et al. 2010, Phillips-Mao et al. 2014), the role of disturbance caused by Lumbricus terrestris and L. rubellus (Nuzzo et al. 2009), and the preferential browsing of white-tailed deer, Odocoileus virginianus on native species (Knight et al. 2009, Kalisz et al. 2014). Alliaria petiolata continues to invade new areas (Welk et al. 2002) and persists in areas where it has become established, although its abundance in invaded areas can decline over time (Davis et al. 2012, Lankau et al. 2009). A largely overlooked aspect of $A$. petiolata's biology is seed dispersal distances and mechanisms (Barney and Whitlow 2008). Closing this knowledge 
93 gap is important for improving our understanding of the invasive ability of $A$. petiolata and how

94 it disperses across the landscape.

95

96

97

98

99

100

101

102

103

104

105

106

107

108

109

110

111

112

113

114

Eschtruth and Battles $(2009,2011,2014)$ studied A. petiolata's ability to invade new areas and found that propagule pressure is the most important factor. The importance of propagule pressure was tested through a propagule pressure model. However, this model was was built on untested dispersal distances assumptions and predicted that $95 \%$ of seeds fall within the maximum reported distance of dispersal of $2 \mathrm{~m}$ as described in Nuzzo (1999) and Drayton and Primack (1999). The reported dispersal distances were based on observations and simple field tests (Nuzzo 1999, Dayton and Primack 1999, Victoria Nuzzo personal communication 2014), not experimental data. Therefore, it is possible that the importance of propagule pressure was not accurately estimated due to the parameters of the underlying model being based on untested assumptions. Experimentally measuring dispersal distances in the field may provide the basis for a more accurate estimate of propagule pressure and its importance in A. petiolata invasion.

If the vast majority of $A$. petiolata seeds are dispersed within $2 \mathrm{~m}$ of the parent plant as reported in Nuzzo (1999) and Drayton and Primack (1999), then A. petiolata populations are predicted to spread at a rate of less than $1 \mathrm{~m}$ per year, which is below the observed average spread rate of $5.4 \mathrm{~m}$ per year (Nuzzo 1999). In addition, $A$. petiolata spreads through the establishment of satellite populations that are well ahead of the invasion front (Nuzzo 1993, 1999; Burls and McClaugherty 2008). Both the rapidly moving invasion front and the establishment of satellite populations suggest the presence of a long-distance dispersal mechanism (Nuzzo 1993, 1999; Burls and McClaugherty 2008; Eschtruth and Battles 2011). 

and stated that seeds did not float well but readily adhered to a damp cloth. Therefore,

117

118

119

120

121

122

123

124

125

126

127

128

129

130

131

132

133

134 135 136 137 epizoochory has been suggested as a possible dispersal mechanism (Blossey 2001, Cavers et al., and Evans et al. 2012) with deer, mice, and other small mammals possibly transporting the seed. But this hypothesis has not been explicitly tested.

The Dispersal Diaspore Database (DDD) (Hintze et al. 2013) contains seed dispersal information for over 2,111 plant species to predict and rank the epizoochory potential of these species by combining two metrics, the ability of a seed to attach to fur (Will et al. 2007), and to be retained in the fur once attached (Römermann et al. 2005; Tackenberg et al. 2006). Of the 2,111 species in the index, 64\% were better adapted to epizoochory than A. petiolata. Alliaria petiolata seeds lack any clear adaptions for epizoochory such as hooks or barbs, but they have several favorable traits including small size and partial exposure in the fruit (Hintze et al. 2013).

While these results are not highly suggestive of epizoochory, they may not have captured $A$. petiolata's true potential for epizoochory. Many plant species are dispersed long distances by a mechanism for which they have no apparent adaptations (Clark et al. 1998; Higgins and Cain 2003; Myers et al. 2004).

Studies that comprise the DDD found that attachment potential and retention potential differed among the European mammal species tested (Tackenberg et al. 2006; Will et al. 2007). Since epizoochory potential differs among mammal species, it is important to conduct epizoochory tests on mammal species that $A$. petiolata is likely to encounter in North America. The mammals mentioned in Blossey (2001) and Evans et al. (2012) are logical animals to test since it was hypothesized they were vectors involved in A. petiolata long distance dispersal. Additionally, the dampness of the fur may also affect epizoochory potential. Tackenberg et al. 
138 (2006) found that fur dampness did not have a consistent effect on the retention potential for all

13919 species they tested, but dampness increased retention potential for a few species. Cavers et al.

140 (1979) noted that $A$. petiolata seeds readily adhered to a damp cloth suggesting that the seeds

141 may be more likely to stick to damp rather than dry fur.

142 Our study had two objectives. The first objective was to experimentally measure $A$.

143 petiolata seed dispersal distances in the field using seed traps and to use these data to estimate

144 the parameters of eight dispersal kernels. The results of our dispersal study were then compared

145 the dispersal function used by Eschtruth and Battles (2009, 2011, 2014). We also used the results

146 of our study to calculate median dispersal distance and distance at which $95 \%$ are dispersed

147 within.

148 Our second objective was to test the hypothesis that epizoochory via North American

149 woodland mammals is a long-distance seed dispersal mechanism in A. petiolata. We tested this

150 hypothesis through field and complimentary laboratory studies. The field study was designed to

151 attract small mammals to experimental areas to determine if high mammal activity caused these

152 areas to accumulate more seeds resulting in higher densities of first-year $A$. petiolata seedlings

153 than in areas with low mammal activity. Laboratory studies measured attachment potential and

154 retention potential of wet and dry $A$. petiolata seeds applied to wet and dry fur of raccoon

155 (Procyon lotor) and white-tailed deer pelts. Our study is the first to experimentally measure $A$.

156 petiolata seed dispersal distances in the field and also to demonstrate that epizoochory is a

157 probable long-distance seed dispersal mechanism.

158 Methods

159 Study Species 
biennial. Germination occurs in late winter or early spring and basal rosettes are formed the first

162

163

164

165

166

167

168

169

170

171

172

173

174

175

176

177

178

year. During early spring of the second year, plants bolt and rapidly increase shoot length with

stem elongation of up to $1.9 \mathrm{~cm}$ per day between the $18^{\text {th }}$ of April and the $13^{\text {th }}$ of May (Anderson et al. 1996). Flowers form in March and April, while fruits develop in May and June. Seeds are small $[($ mean \pm SE, L x W, 3.6 $\pm 0.05 \times 1.3 \pm 0.03 \mathrm{~mm})$, range L (3.1-4.5 mm) and W (0.9 -1.9 mm), $\mathrm{N}=50$ ] (Loebach and Anderson 2017) and Mullarkey et al. (2013) reported that seed mass varied from $2.11 \pm 0.04$ to $2.38 \pm 0.034$ ) depending upon cross type (e.g., within populations, between populations, or selfing). According to Anderson et al. (1996), seeds are dispersed from July to October with peaks occurring in August and September. Baskin and Baskin (1992) found that 70\% of seeds germinated in the first year under favorable conditions, but seeds can persist in the seed bank up to five years (Baskin and Baskin 1992).

Study Sites

Study sites were located within two properties of the Parklands Foundation, the Merwin Nature Preserve and South Breens Woods. The Merwin Nature Preserve is $25 \mathrm{~km}$ and South Breens Woods is $20 \mathrm{~km}$ north of Normal, IL USA. The Merwin Nature Preserve is a 325 ha oakhickory dominated second-growth forest that has been protected from livestock grazing since the 1970's. The South Breens Woods is a 4 ha oak dominated forest and has been under protection since 1979. Dominant tree species at Parklands

Dominant tree species at the Merwin study area are Ohio buckeye (Aesculus glabra), hackberry (Celtis occidentalisi), American elm (Ulmus americana), yellowbud hickory (Carya cordiformis), and black walnut (Juglans nigra). The dominant ground layer species are wood nettle (Laportea canadensis), black snake root (Sanicula odorata), wing stem (Verbesina 
183 alternifolia), Virginia wildrye (Elymus virginicus), and Virginia creeper (Parthenocissus

184 quinquefolia). The mapped soil type is straw loam (224C2).

185 At Breens Woods, the dominant tree species are white oak (Quercus alba), American 186 elm, red elm (Ulmus rubra), black cherry (Prunus serotina), and iron wood (Ostrya virginiana).

187 The dominant ground species are Virginia creeper, Solomon seal (Polygonatum commutatum), 188 false Solomon seal (Smilicina racemosa), jack in the pulpit (Arisaema triphyllum), and sweet189 scented bedstraw (Galium triflorum). The mapped soil type is Birbeck silt loam (233B2) (Soil 190 Survey of McLean County, Illinois, 2004).

Alliaria petiolata was present and abundant at both sites as were other invasive species

192 193

such as buckthorn (Rhamnus cathartica) and honeysuckle (Lonicera maackii).

Seed Trap Design

Our experiment was designed to determine the $A$. petiolata dispersed seed density at increasing distances away from the seed source and to use these data to estimate the parameters of the eight dispersal kernels. A dispersal kernel is a probability density function (pdf) that describes the dispersal of seeds from a parent plant (Clarke et al. 1999). There are two types of dispersal kernels, the dispersal location kernel, $g(r)$, and the dispersal distance kernel, $f(r)$ (Nathan et al. 2012). The $g(r)$ describes the probability of a seed dispersing into an infinitely small area at a given distance from the parent plant and it can be used to predict the number of seeds that are expected to land in a specific area at a specific distance from the seed source (Schurr et al. 2008). The eight $g(r)$ described in Cousens et al. (2008) was used in this study (Table 1). We compared the predictions of the $g(r)$ from our study to the negative exponential function used by Eschtruth and Battles (2009, 2011, 2014). 
calculate median dispersal distance and distance at which 95\% are dispersed within (Cousens et

207

208

209

210

211

212

213

214

215

216

217

218

219

220

221

222

223

224

225

226

227 al. 2008).

Typically, a pdf is generated through the use of seed traps placed in a specific design around a seed source (Bullock et al. 2006). A mathematical function describing a $g(r)$ is fitted to the trap data to estimate the shape of the dispersal kernel. Assuming dispersal is isotropic, the same in all directions, the calculated $g(r)$ can be converted to the $f(r)$ with the equation:

$$
f(r)=2 \pi r g(r)
$$

eqn. 1

(Cousens and Rawlinson 2001).

The seed dispersal study was conducted at Merwin Nature Preserve. Alliaria petiolata seed point sources were established in areas where there were no trees or shrubs within $3.5 \mathrm{~m}$, where understory vegetation cover was less than $20 \%$, and where there was nearly level topography. Sites were also located within the interior of the woodlands with a full canopy. Sites were selected for these characteristics to minimize variation in dispersal distances due to the surrounding vegetation and gravity.

An A. petiolata seed point source consisted of 15 second-year $A$. petiolata plants transplanted into a single $0.25 \mathrm{~m}$ radius circle. The 15 plants were randomly located within the circle. In total, three point sources were created. Plants were transplanted during the late stages of fruit development just prior to the beginning of dehiscence. Since isolation is important for increasing the effectiveness of this experimental design (Bullock et al. 2006), all second-year $A$. petiolata plants within $9 \mathrm{~m}$ of the point source were removed. In the area beyond the $9 \mathrm{~m}$, scattered $A$. petiolata plants occurred, but there were no dense stands. Dispersal was assumed to be isotropic (the same in all directions). To capture the seed rain, seed traps were placed at 
228 intervals of increasing distance around the point source in a sector design, which is the most

229 effective design for assessing isotropic dispersal (Skarpaas et al. 2005). One sector consisted of

23045 azimuth degrees beginning at zero degrees north for a total of eight sectors. Within a sector,

231 traps were placed at distances $0.25,0.50,0.75,1.25,2.25,3.25 \mathrm{~m}$ from the center of the point

232 source. In each sector, one trap was placed at distances $0.25,0.50$, and $0.75 \mathrm{~m}$, two traps at 1.25

$233 \mathrm{~m}$, four at $2.25 \mathrm{~m}$, and six at $3.25 \mathrm{~m}$ from the point source (Fig. 1). The number of traps

234 increased as a step function as distance from the point source increased to maintain a reasonable

235 probability of capturing a seed as distance increased. The number of traps was not increased until

236 after $0.75 \mathrm{~m}$ to keep the total quantity of traps to a feasible number (Bullock and Clarke 2000).

237 Seed traps consisted of two plastic cups with diameter of $9.5 \mathrm{~cm}$ and height of $12 \mathrm{~cm}$.

238 One cup was placed inside the other and nylon cloth was placed between the cups. Several small

239 holes were inserted into the bottom of both cups for water drainage while the cloth captured the

240 seeds. Each trap was placed in a hole slightly larger than the cup's diameter and deep enough so

241 the top of the trap was flush with the ground surface. At distances with more than one trap, traps

242 were placed so each touched its neighbor and all were equidistant from the center of the point

243 source. For each point source, there was a total of 120 traps for $0.855 \mathrm{~m}^{2}$ of trapping area.

244 Seed traps were placed around one point source in summer 2013 (Point Source 1) and

245 two point sources in 2014 (Point Sources 2 and 3). Traps were placed around the point source

246 before the siliques began dehiscence and were collected after the vast majority of seeds

247 dispersed. Traps were in the field from July $24^{\text {th }}$ to October $5^{\text {th }}$ and July $12^{\text {th }}$ to August $28^{\text {th }}$ for

2482013 and 2014, respectively. After the seed traps were collected, the numbers of seeds in each

249 trap were counted in the laboratory at Illinois State University. 
The total number of seeds dispersed from a point source was estimated by subtracting the

251

252

253

254

255

256

257

258

259

260

261

262

263

264

265

266

267

268

269

270

271

272

number of seeds that were not dispersed from each point source at the end of the experiment,

from the estimated total at the beginning. To estimate the initial total number of seeds in a point source, the length of each silique was measured and the number of seeds inside was estimated with the equation $S=-6.8+4.38 x\left(\mathrm{~F}_{1,138}=419.5, \mathrm{p}<0.0001, \mathrm{R}^{2}=0.752\right) . S$ is seed number and $x$ is silique length in $\mathrm{cm}$ (Loebach and Anderson 2018). When seed traps were collected, the siliques remaining in the point source were also collected and the seeds within them were counted in the laboratory.

\section{Estimating Dispersal Kernels}

Seed count data from the three $A$. petiolata seed point sources were used to estimate the parameters of eight different $g(r)$ dispersal functions that are described in Nathan et al. (2012).

These functions include a scale parameter $(a)$ and a shape parameter $(b)$, except for the Gaussian and negative exponential functions, which only have the $a$ parameter. Since dispersal was assumed to be isotropic, direction was ignored when fitting the $g(r)$ functions. While there was variation in seed counts among the directions, there was no consistent pattern. Also, assuming isotropic dispersal allows for more general predictions about dispersal distances to be made than if directions were analyzed separately. Lastly, there are no known a priori reasons for why directions would differ.

For each point source, the $g(r)$ functions were fitted to the seed count data using the following equation:

$$
n=g(r) A Q
$$

where the parameter $n$ was the seed number captured by a trap, $g(r)$ was one of the eight functions evaluated at distance $r, A$ was the area of a seed trap $\left(0.007125 \mathrm{~m}^{2}\right)$, and $Q$ was the 
273 estimated number of seeds within the point source around which the trap was located. Parameter

274 values for the dispersal functions were estimated by non-linear mixed effects modelling, which

275 minimizes the negative $\log$-likelihood value $(-\ln L)$ using maximum likelihood (PROC

276 NLMIXED) in SAS ${ }^{\circledR}$ software 9.3 (SAS Institute 2012). The default quasi-Newton algorithm

277 was used. The product $A Q$ was included as an offset variable as suggested by Cousens et al.

278 (2008). An additional random effect parameter $(u)$ was included to account for random variation 279 among the three point sources.

Dispersal functions were fit to the data using a log-link function and a negative binomial error distribution. A Poisson distribution was also utilized, but in all cases the negative binomial had a better fit. The negative binomial distribution assumes seeds are distributed with a mean of $N$ and the dispersion parameter $k$, which accounts for over dispersion (Clark et al. 2005). The dispersal function with the lowest Akaike Information Criterion (AIC) score was selected for all further analysis (Johnson and Omland 2004). requirements are that the function must be positive over the entire expressed space and the function must integrate to one (Cousens and Rawlinson 2001). The selected $g(r)$ was then converted to the $f(r)$ with equation 1 . The $f(r)$ was evaluated to determine if it met the requirements of a pdf (Peart 1985). The $g(r)$ and resultant $f(r)$ with the lowest AIC score, and that met the requirements of a pdf, were selected. dispersed into an infinitely small area decreased as distance from the point source increased. The $g(r)$ was used to predict the number seeds that would arrive in an area through equation 2 . These predictions were then compared to the actual seed counts from the field. The selected $g(r)$ 
296 function was also compared to the negative exponential from Eschtruth and Battles (2009) by

297 using both functions to predict the change in dispersed seed density as distance increased from a

298 single second-year $A$. petiolata plant. The fecundity of $A$. petiolata plants was set to 156 seeds as

299 this was the fecundity value used in Eschtruth and Battles (2009). The $f(r)$ was analyzed to

300 calculate the median dispersal distance and the distance at which $95 \%$ of seed are dispersed by

301 determining the distance at which the $f(r)$ integrated to 0.50 and 0.95 , respectively.

302 Epizoochory Field Experiment

303 To determine if epizoochory occurs in the field, we placed experimental blocks around 304 dense patches of second-year A. petiolata plants. In the summer of 2013, blocks were established around the perimeter of three A. petiolata patches at the Merwin Nature Preserve. In 2014, blocks were established around one $A$. petiolata patch at Merwin Nature Preserve and at three patches at South Breens Woods. At each A. petiolata patch, one block was placed at the outer edge of the patch in each of the four cardinal directions from the patch center for a total of four blocks per patch. In total, there were 28 blocks placed around seven $A$. petiolata patches. Each block contained a mammal inclusion treatment (MIT) and a control. In both treatments, a germination tray filled with potting soil was placed into the ground so it was flush with the ground surface. The MIT was designed to increase mammal activity over germination trays relative to the control. A control replicate consisted of a wood-frame $(11 \times 61 \times 31 \mathrm{~cm})$ completely covered with $1.2 \mathrm{~cm}^{2}$ size wire mesh placed over a germination tray. A MIT replicate consisted of a wooden frame $(31 \times 61 \times 31 \mathrm{~cm})$ covered with $2.5 \mathrm{~cm}$ mesh poultry fencing placed over a tray. The two $31 \times 31 \mathrm{~cm}$ ends of the MIT were not covered to allow raccoon-sized or smaller animals to enter. Each frame included a shallow metal pie pan (23 cm diameter) attached

318 to bottom in the center. Only pans in the MIT were filled daily with bait ( $200 \mathrm{ml}$ equal parts of 
319 cracked corn and black oil sunflower seeds) to attract mammals. Within a block, the position of

320 the MIT and control were randomly assigned and were placed $1 \mathrm{~m}$ apart. All second-year $A$.

321 petiolata plants located within $1.5 \mathrm{~m}$ of the block were removed to prevent significant amounts

322 of seed rain from falling into the trays. One motion sensitive camera was placed at each patch to

323 record animal activity around a single block. The MIT and control were both captured within the

324 frame of the camera.

325 The distance between the blocks placed on the north and south sides of the patch and

326 between the blocks on east and west sides was measured. A sampling line was established

327 between the two blocks that were the furthest apart. Ten equally spaced sampling points were

328 established along the line. At each sampling point, a $0.25 \mathrm{~m}^{2}$ quadrant was placed a random

329 distance between 0 and $100 \mathrm{~cm}$ from the transect line and the number of second-year A. petiolata

330 plants were counted. This was done to estimate the average density of second-year plants per 1

$331 \mathrm{~m}^{2}$.

332 Trays were placed in the field during peak seed dispersal. In 2013, the trays were in the

333 field from July $3^{\text {rd }}$ to August $7^{\text {th }}$. In 2014, at South Breens Woods trays were in field from July

$3342^{\text {nd }}$ to August $8^{\text {th }}$ while at Merwin Nature Preserve trays were out from July $8^{\text {th }}$ to August $8^{\text {th }}$.

335 After the trays were collected, they were transported to Illinois State University to overwinter

336 outdoors since cold-moist stratification is necessary for seed germination (Baskin and Baskin

337 1992). The trays were moved to a heated greenhouse on Feb $20^{\text {th }}$ in 2014 and Feb $16^{\text {th }}$ in 2015.

338 Alliaria petiolata seedlings were counted daily until no new seedlings were observed on two

339 consecutive days, because by this time $95 \%$ of the trays had no new seedlings for five

340 consecutive days. Counting was terminated on March $22^{\text {nd }}$ and $12^{\text {th }}$ in 2014 and 2015,

341 respectively. The majority of seed within the trays are likely to have germinated since $70 \%$ of $A$. 
342 petiolata seeds germinate the first year. Also, there is no known reason why germination rates

343 would differ between the MIT and control trays.

The number of animal visits in the photos recorded by the motion sensitive cameras was

345 counted for each treatment. An animal was considered to have visited the MIT treatment if it

346 entered the frame, while a visit to the control was counted if an animal touched the outside of the

347 frame. Photos were analyzed using a chi-square analysis to determine if there was a significant

348 difference in animal visits between the treatments. The A. petiolata seedling counts in the

349 germination trays were analyzed with a mixed linear model (PROC MIXED) to test for a

350 significant difference between the control and MIT. Treatment was a fixed effect while block,

351 block nested within A. petiolata patch, and year were included as random effects in the model.

352 The data were square root transformed to meet the assumptions of normality. All statistical tests

353 were performed in $\mathrm{SAS}^{\circledR}$ software 9.3 (SAS Institute 2012). Alpha levels were set at 0.05 for all

354 tests. This project was approved by the Illinois State University Institutional Animal Care and

355 Use Committee (IACUC). The IACUC number 14-2013.

\section{Seed Attachment}

The attachment potential of $A$. petiolata seeds was measured using a white-tailed deer

358

359

360

361

362

363

364

and a raccoon pelt. Both of these animals are common within the study sites and across North America. The pelts consisted of the skin of the animal with the fur still attached. The deer fur consisted of 2-3 cm long hairs that were flattened from the front of the animal towards the back.

The raccoon fur had 5-6 cm long hairs with many smaller hairs, less than $4 \mathrm{~cm}$ underneath forming a thick undercoat. Both hair types generally stood upright. The pelts were placed between two wood boards with a $25 \times 25 \mathrm{~cm}$ opening leaving that area of fur uncovered. The two boards were clamped together to secure the pelts. A 9x16 cm grid of 144, 2x2 cm squares was 
365

366

367

368

369

370

371

372

373

374

375

376

377

378

379

380

381

382

383

384

385

386

387

centered $15 \mathrm{~cm}$ above the fur in a horizontal position with the fur side up. In each trial, $100 \mathrm{~A}$.

petiolata seeds were dropped singly through randomly selected squares onto the fur. The pelt and

frame were then rotated 180 degrees over a collection box and then immediately turned back to

the original position. The number of seeds that remained attached to the fur were counted.

Attachment potential was measured as the proportion of seeds that remained attached to the furs

after they were rotated. To determine if attachment potential differed between dry and wet fur,

furs were misted with $40 \mathrm{ml}$ of water using a plastic spray bottle before the seeds were dropped.

The moisture of seeds was also manipulated by partially submerging the seeds in water before

they were dropped onto the fur.

For each fur type (racoon or deer), ten replicates trials were used for each of the four

treatment combinations, seed dry and fur dry (SD/FD), seed dry and fur wet ( $\mathrm{SD} / \mathrm{FW})$, seed wet

and fur dry (SW/FD), and seed wet and fur wet (SW/FW) for a total of 40 trials per fur type. The

raccoon and deer furs were analyzed separately.

To test for a significant effect of seed condition, fur condition and their interaction, the

data were aligned and rank transformed (ART) since they could not be transformed to meet

assumptions of a parametric Analysis of Variance (ANOVA). Data were aligned by removing

the marginal means of all other factors from the response variable other than the factor for which

the alignment was being applied (Wobbrock et al. 2011). For example, to analyze the interaction

effect of a two-way factorial, the marginal means of the main effects are removed from each

response variable to isolate the interaction effect. The aligned data were then ranked, and a twoway ANOVA (PROC GLM; SAS Institute 2012) was performed on the ranks. Separate

ANOVAs were performed for each main effect and the interaction. For a significant interaction,

a Tukey post-hoc analysis was performed. The data were aligned and ranked using the ARTool 
388 (Wobbrock et al. 2011). The ART is an appropriate alternative to parametric F-tests when 389 analyzing factorial designs (Mansouri et al. 2004). The ART is robust to Type 1 error (Mansouri 390 1999) and has greater power than parametric F-tests when normality assumptions are not met 391 (Richter and Payton 1999).

392 Seed Retention

The same deer and raccoon pelts were attached to separate $25 \times 38 \mathrm{~cm}$ sections of

394 396

397

400

401

402

403

404

405

406

407

408

409

410

cardboard. Before seeds were attached, the furs were homogenized by combing the furs two times horizontally and vertically using a plastic comb with $4 \mathrm{~cm}$ long teeth spaced $0.9 \mathrm{~cm}$ apart. A $5 \times 10$ grid of $2 \times 2 \mathrm{~cm}$ cells was placed over the furs and two seeds were dropped per cell from a height of $2 \mathrm{~cm}$. Seeds were then combed into the fur with the same method as homogenization. This procedure is similar to previous epizoochory studies (Rommerman et al. 2005; Tackenberg et al. 2006; and Pablos and Peco 2007). The furs were rotated 180 degrees over a collection box to collect the seeds that did not attach. Next the furs were clamped to a collection bin that was attached to a Fisher Vortex Genie 2, which shook the fur and bin horizontally for 1 hour. The Fisher Vortex abruptly moved the furs back and forth $0.5 \mathrm{~cm}$. The numbers of horizontal movements were counted for 1 minute during the first minute, 30th minute, and 59th minute to ensure that each trial had between 145 to 155 movements per minute. To test for the effect of moisture, furs were misted with water with the same process as described in the attachment potential experiment after the seeds were combed into the fur. There were five trials for each fur by moisture combination.

Other studies (Rommerman et al. 2005; Tackenberg et al. 2006; and Pablos and Peco 2007) used a specialized shaking machine that was able to shake furs horizontally and vertically to test for an effect of position on seed retention potential. We were unable to test the effect of 
411 fur position since the Fisher Vortex Genie 2 is only capable of moving furs horizontally.

412 However, the results of this study are likely comparable to other studies since fur position was

413 found to have no effect on retention potential (Tackenberg et al. 2006), or only an effect for

414 cattle fur (Pablos and Peco 2007), which was not used in this study.

415 Retention potential was measured as the proportion of seeds that remained attached after

4161 hour of shaking. For each pelt type, a two-sample t-test (PROC TTEST; SAS Institute 2012)

417 was done to determine if the retention potential was significantly different between wet and dry

418 fur. Unequal variances were assumed and the Satterwaite's test was used as an alternative to the

419 Student's t-test (Ruxton 2006). The mean retention potential was considered significantly greater

420 than zero if the $95 \%$ confidence intervals did not overlap with zero.

421 Results

422 Dispersal Kernels

423 The estimated number of seeds released from the three point sources was 4012, 4020 and

4244815 for Point Sources 1, 2, and 3, respectively. The total number and percentage of seeds

425 captured from the point sources was $384(9.57 \%), 629$ (15.65\%), and 682 (14.16\%) for Point

426 Sources 1, 2, and 3, respectively. For all three point sources, the mean number of seeds captured

427 per trap was highest in traps placed at distance $0.25 \mathrm{~m}$, and this number decreased as distance

428 from the point source increased (Table 2). Point Source 1 had the lowest mean number of seeds

429 per trap at distance $0.25 \mathrm{~m}$ with $23.4 \pm 6.47$ seeds per trap and Point Source 2 had the highest with

$43049.6( \pm 10.51)$. A small number of seeds was dispersed $2.25 \mathrm{~m}$ with all three point sources

431 averaging less than one seed per trap. Even fewer seeds were dispersed $3.25 \mathrm{~m}$ with all point

432 sources averaging below 0.5 seeds per trap (Table 2). 
434 Weibull function had the lowest AIC score, but the $g(r)$ and $f(r)$ functions did not integrate to one. Because the Weibull did not meet the pdf requirement, the lognormal function was selected next for analysis since it had the next lowest AIC score at 1020.4 and the $g(r)$ and $f(r)$ met the requirements of a pdf. However, the $g(r)$ of the lognormal function predicted that the probability density of a seed dispersing into an infinitely small area was zero at distance zero. This prediction was in direct contradiction with field observations that many seeds fall directly below the parent plant, which should result in the density probability being greater than zero at distance zero. Because of this unrealistic prediction, the lognormal function was not used for further 442 analysis.

The 2Dt kernel had the next lowest AIC score after the lognormal at 1025.5 and the $g(r)$ and $f(r)$ met the requirements of a pdf. The $2 \mathrm{Dt} \mathrm{g}(r)$ kernel predicted that the probability density of a seed landing in an infinitely small area is highest at distance zero and then steadily declines until $1 \mathrm{~m}$ (Fig. 2). This result is more in agreement with field observations and is different than the lognormal. Beyond $0.25 \mathrm{~m}$, the $\mathrm{g}(r)$ 's probability densities of the 2Dt rapidly declined as distance increased to $1 \mathrm{~m}$. As the distance increased beyond $1 \mathrm{~m}$, the probability density asymptotically approached zero. each of the point sources separately. The $2 \mathrm{Dt}$ function predicts that the seed count per trap is

452 highest at $0 \mathrm{~m}$ and then the predicted count steadily decreases until $1.30 \mathrm{~m}$, where less than one 453 seed per trap is predicted. The predicted seed count per trap continues to decrease beyond $1.30 \mathrm{~m}$ 454 asymptotically approaching zero (Fig. 3). 
The predicted change in dispersed seed density from a single second-year plant as

456 predicted by the $2 \mathrm{Dt} g(r)$ function differs from the prediction of the negative exponential

457 function from Eschtruth and Battles (2009). Specifically, the negative exponential function

458 predicts dispersed seed density to be higher than the $2 \mathrm{Dt}$ function at $0.5 \mathrm{~m}$ and beyond from the 459 point source (Fig. 4).

460 The corresponding $f(r)$ of the 2Dt function has a probability density of zero at distance 461 zero, which is a condition any $f(r)$ will meet due to the multiplier $r$ equaling zero at distance zero 462 in equation 1 . The probability density of the $2 \mathrm{Dt}$ function rapidly increases between 0 and $0.25 \mathrm{~m}$ 463 and peaks at $0.35 \mathrm{~m}$, meaning seeds have the highest probability of dispersing this distance (Fig.

464 5). The probability density then steadily declines to around $1.20 \mathrm{~m}$ and asymptotically

465 approaches zero beyond that distance. The median, mean, and the distance at which $95 \%$ of 466 seeds were dispersed within are $0.47,0.53$ and $1.14 \mathrm{~m}$.

467 The parameter values for the 2Dt function were based on the pooled data of the three 468 replicate plots (Table 3). SAS approximates the standard errors, P-values are for alpha $<0.05$ and 469 hypothesis of parameter $=0$. Variation in seed counts within traps was not significantly different 470 among the three point sources as the parameter $u$ was not significantly different than zero. The 471 parameter $k$ was less than one, which indicates that there was a high amount of variation around

472 the expected seed trap values (Clark et al 2005). The high variation is apparent when comparing 473 the predicted seed counts per trap of the dispersal functions to the actual seed counts from the 474 traps in the field (Fig. 3). There was a large amount of variability in the number of seeds 475 captured at distances 0.25 and $0.5 \mathrm{~m}$. At the $0.25 \mathrm{~m}$ distance, captured seeds varied from 3 seeds 476 to 117 seeds per trap, and from 2 to 59 at $0.5 \mathrm{~m}$ distance.

\section{Epizoochory Field Experiment}


479 animals were visiting the treatments with a high frequency. This high level of animal activity at 480 the MIT was supported by the photos from the motion sensitive cameras. For both years and all 481 A. petiolata patches combined, the MIT had 951 animal visits, which was significantly greater $482\left(\chi_{(1,982)}^{2}=788.6, p<0.0001\right)$ than the 51 visits to the controls. Raccoons accounted for most 483 animal visits and were the only animal recorded at all seven $A$. petiolata patches (Table 4). 484 Raccoons entered the MIT wood frames and stood directly over the germination trays while 485 feeding. Turkeys (Meleagris gallopavo) were the second most common animal visitor, but they 486 were only recorded in the year 2014 and only at the South Breen Woods. Turkeys and deer were 487 photographed eating the bait by inserting only their head into the open end of the frame. The 488 increased animal activity over the MIT germination trays resulted in significantly more $489\left(\mathrm{~F}_{1,27}=129.5, \mathrm{p}<0.0001\right)$ A. petiolata seedlings than in control trays with average MIT counts 490 more than one order of magnitude greater than for the control trays (Fig. 6).

492 of second-year plants (Table 5). While the A. petiolata patches differed in size, there appeared to 493 be no pattern to the variation unlike second-year plant density. All patches from summer 2014 494 had lower second-year plant density than patches from 2013. However, this difference in density 495 did not affect $A$. petiolata seedling counts in the germination trays. The random variation attributable to $A$. petiolata patch and year to seedling counts were not significant ( $\mathrm{p}>0.10$ for

497 both). The variation due to block was estimated to be zero; therefore, SAS PROC MIXED did 498 not test for significance.

499 Seed Attachment 
$501 \quad\left(\mathrm{~F}_{1,39}=110.3, \mathrm{P}<0.0001\right)$ conditions, and their interaction $\left(\mathrm{F}_{1,39}=59.8, \mathrm{P}<0.0001\right)$ significantly

502 affected attachment potential. Fur $\left(\mathrm{F}_{1,39}=3920.4, \mathrm{P}<0.0001\right)$ and seed conditions

$503\left(\mathrm{~F}_{1,39}=100.39, \mathrm{P}<0.0001\right)$, and their interaction $\left(\mathrm{F}_{1,39}=81.29, \mathrm{P}<0.0001\right)$ also significantly affected

504 attachment potential on the raccoon pelt. Seed attachment potential was highest for both pelt

505 types when seeds were wet, regardless of fur condition (Fig. 7a). When seeds were dry, more 506 seeds attached to wet fur than dry fur.

507 The Tukey follow-up test of the interaction term found significant differences in the ART 508 ranks. For both pelt types, the SD/FW and the SW/FD treatments had significantly higher ranks 509 than the SD/FD and the SW/FW treatments (Fig. 7b). For the SW/FD treatment, the weak effect

510 on attachment potential of the dry fur was overcome by the wet seed resulting in a high

511 attachment potential. For the SD/FW treatment, the weak effect of the dry seed was overcome by

512 the effect of the wet fur resulting again in a high attachment potential. Low ART values for

$513 \mathrm{SW} / \mathrm{FW}$ treatment, despite high attachment potential values, were due to strong positive effects

514 on attachment potential of both wet fur and wet seeds, with no increase in attachment potential in

515 the combined treatment. Thus, high attachment potential values will result, if either the seed or 516 fur is wet.

517 Seed Retention

518 The retention potential was significantly greater for wet deer fur $\left(\mathrm{T}_{4.63}=29.6 \mathrm{p}<0.0001\right)$

519 and wet raccoon fur $\left(\mathrm{T}_{7.27}=74.78, \mathrm{p}<0.0001\right)$ when compared to dry fur (Fig. 8). The difference

520 in retention potential between wet and dry fur was large for both pelt types. For raccoon fur,

521 values ranged from $2-5 \%$ for dry fur compared to $94-100 \%$ for wet fur; for deer fur, values

522 ranged from $1-6 \%$ for dry fur from $81-98 \%$ for wet fur. While the retention potential was 
523 significantly lower for dry fur, it was still significantly greater than zero since the $95 \%$

524 confidence intervals did not overlap with zero.

\section{Discussion}

526 The results from this experimental study provide a more accurate and precise prediction 527 of dispersal distances in A. petiolata than those available in the literature (Nuzzo 1999; Drayton 528 and Primack 1999), although the estimates from prior studies predict that most seeds fell within 529 1-2 $\mathrm{m}$ of the parent plants are consistent with our results. The mean and median seed dispersal 530 distances predicted by the 2Dt function were about $0.50 \mathrm{~m}$, which is substantially less than the $5311.28 \mathrm{~m}$ (range 1.03-1.63m) predicted by Biswas and Wagner (2015) who used an experimental 532 design similar to ours. However, the first seed traps in that study were placed $0.50 \mathrm{~m}$ from the

533 point seed source which may have resulted in the majority of dispersed seeds being missed as our 534 results indicate peak seed dispersal occurred at 0.35 . This likely caused the average dispersal to 535 be overestimated.

536 The 2Dt function predicted that the distance at which $95 \%$ of $A$. petiolata seeds are

537 dispersed is about $1.14 \mathrm{~m}$, which is substantially less than the $2 \mathrm{~m}$ used to estimate the value of

538 the $b$ parameter of the negative exponential function used by Eschtruth and Battles $(2009,2011$, 539 2014) suggesting an overestimation of seed dispersal distances in the studies. The

540 overestimation of dispersal distances is also apparent when the predicted dispersed seed density

541 of the negative exponential function is compared to that of the 2Dt function (Fig. 4). The

542 negative exponential overestimates dispersed seed density at distances greater than $0.50 \mathrm{~m}$. By

543 overestimating dispersal distances, the seed rain index of Eschtruth and Battles $(2009,2011$,

544 2014) also overestimated the seed rain entering their research plots, which resulted in an over

545 estimation of propagule pressure. Incorporating the experimentally based dispersal functions 
546 from this study will improve the accuracy of estimates of seed rain, and therefore, propagule 547 pressure.

548 With only $5 \%$ of $A$. petiolata seeds being dispersed over $1.14 \mathrm{~m}$ (Fig. 3), A. petiolata is

549 similar to most plant species in that the vast majority of seeds are dispersed within a short

550 distance from the parent plant (Wilson 1993; Kot et al. 1996; Venable et al. 2008) with only a

551 small proportion dispersed long distances (Cain et al. 2000; Nathan 2006; Nathan et al. 2008).

552 However, these relatively rare long-distance dispersal events are more important to the spread of

553 a species across the landscape that many short distance dispersal events (Clark et al. 1998;

554 Suarez et al. 2001; Nathan et al. 2003; Theoharides and Dukes 2007; Pergl et al. 2011). Our

555 results indicate the epizoochory is likely one mechanism by which seeds can be dispersed greater

556 distances.

557 This study is the first to provide experimental evidence that epizoochory through

558 woodland animals is a potential seed dispersal mechanism of $A$. petiolata. The MIT germination

559 trays had significantly more animal visits than the control trays (Table 4) which resulted in the

560 MIT trays having significantly more $A$. petiolata seedlings (Fig. 6). The laboratory studies

561 provide evidence that seeds can adhere to raccoon and deer fur sufficiently for dispersal (Fig. 7

562 and 8). However, these results do not rule out the possibility of seeds being dispersed by

563 attachment to hooves, paws, or claws (Gill and Beardall 2001; Heinken et al. 2006; Schulze et al.

564 2014). Since attachment and retention potential increased when seeds or fur were wet (Fig. 7 and

565 8) it is likely wet environmental conditions, such as rainfall or heavy dew, increase A. petiolata

566 epizoochory potential.

567 Alliaria petiolata seeds that are retained within deer and raccoon fur have the potential to

568 be dispersed several kilometers by these animals. The longer a seed is retained in the fur of an 
569 animal, the farther it can be dispersed by that animal (Couvreur et al. 2005; Adriaens et al. 2007;

570 Guttal et al. 2011), particularly with larger home ranges. The home range size of deer can range

571 from less $1 \mathrm{~km}^{2}$ to more than $10 \mathrm{~km}^{2}$ depending on season and age of the deer (Lesage et al.

572 2000). The home range size of raccoons can range from less than $0.5 \mathrm{~km}^{2}$ to more than $1 \mathrm{~km}^{2}$

573 depending on resource availability and season (Gerht and Fritzel 1998, Beasley et al. 2007).

574 While $A$. petiolata seeds lack clear adaptations for epizoochory, other studies have also

575 found that seeds without special adaptations for animal dispersal exhibit epizoochory, albeit at a

576 lower proportion of total seed production compared to plant species with specific adaptations

577 (Fisher et al. et al. 1996; Courvreur et al. 2004; Hovstad et al. 2009). A lack of adaptations by A.

578 petiolata may be compensated for by high seed production (Anderson et al. 1996; Nuzzo 1999;

579 Susko and Lovett-Doust 2000, Will and Tackenberg 2008; Couvreur et al. 2008). Additionally,

580 autogamy in $A$. petiolata can allow establishment of new populations from a small number of

581 dispersed seeds (Anderson et al. 1996). Therefore, epizoochory may be an important mechanism

582 for the spread of $A$. petiolata across the landscape accounting for rates of expansion greater than

583 predicted rate of less than $1 \mathrm{~m}$ per year (Nuzzo 1999). Epizoochory may also contribute to $A$.

584 petiolata's invasion success as it may increase the probability that seeds are deposited on

585 favorable microsites within woodlands (Nathan and Muller-Landau 2000).

586 Endozoochory (seed dispersal in animal guts) is another common seed dispersal

587 mechanism, but it is highly unlikely that that it is a dispersal mechanism of A. petiolata. Alliaria

588 petiolata experiences very little herbivory (Evans and Landis 2007, Riper et al. 2010) due to

589 production of toxins in plant tissues such as cyanide and glucosinolates (Barto et al. 2010,

590 Cipollini and Barto 2007). Hydrochory (seed dispersal through water) has been suggested as a

591 seed dispersal mechanism of $A$. petiolata due to it being prevalent in floodplain areas (Nuzzo 
592 1999, Meekins and McCarthy 2001). While hydrochory may occur, this does not explain how $A$. 593 petiolata spreads into upland areas (Burls and McClaugherty 2008), spreads up stream (Nuzzo 594 1993), or disperses locally across the landscape (Eschtruth and Battles 2009). Hydrochory also 595 does not explain the $A$. petiolata seedling differences between the MIT and control germination 596 trays, because the two treatments did not experience any differences in the flow of water from 597 the ground surface into the trays.

598 Causes for increased attachment retention potential, and attachment potential, when the 599 seed or fur are wet is unclear. Some plant species produce seed coat mucilage when wet 600 increasing epizoochory (Yang et al. 2012). When A. petiolata seeds were observed under a light 601 microscope, they did not appear to produce any mucilage when wet. Another possibility is that 602 the water forms hydrogen bonds between the seeds and fur which increases the retention and 603 attachment potential. However, this idea was not explored in this study and further research is 604 needed to understand the role of water as a dispersal agent for $A$. petiolata.

605 Another topic that needs further clarification is the role genetic and environmental 606 variation plays in $A$. petiolata seed dispersal. Byers and Quinn (1991) found that certain $A$. 607 petiolata traits, such as seed mass, differed among studied habitats. Susko and Lovett-Doust 608 (2000) reported that $A$. petiolata seed mass was highly variable among and within populations. It 609 is unknown how the variability in such traits as seed mass may affect seed dispersal distances. 610 Environmental effects on $A$. petiolata also need to be studied as other studies have found that 611 such factors as habitat type affects dispersal distances (Fontúrbela et al. 2017). It will be 612 important to study these factors to further improve seed dispersal estimates of A. petiolata. 


\section{Acknowledgements}

616 We thank the ParkLands Foundation for allowing us to conduct this research on their

617 property and Victoria A. Borowicz and Scott K. Sakaluk for assistance with this research.

618

619

620

621

622

623

624

625

626

627

628

629

630

631

632

633

634

635

636

637

638

639

640

641

642

643

644

645

646

647

648

649

650

651

652

653

654

655

656

657 
658

659

660

661

662

663

664

665

666

667

668

669

670

671

672

673

674

675

676

677

678

679

680

681

682

683

684

685

686

687

688

689

\section{References}

Adriaens D, Honnay O, Hermy M. 2007. Does seed retention potential affect the distribution of plant species in highly fragmented calcareous grasslands? Ecography (Cop) 30:505-514. doi: $10.1111 / \mathrm{j} .2006 .0906-7590.05049 . x$

Anderson RC, Dhillion SS, Kelley TM. 1996. Aspects of the ecology of an invasive plant, garlic mustard (Alliaria petiolata) in Central Illinois. Restoration Ecology 4:181-191.

Barney JN, Whitlow TH. 2008. A unifying framework for biological invasions: The state factor model. Biological Invasions 10:259-272. doi: 10.1007/s10530-007-9127-8

Barto KE, Powell JR, Cipollini D. 2010. How novel are the chemical weapons of garlic mustard in North American forest understories? Biological Invasions 12:3465-3471.

Baskin JM, Baskin CC. 1992. Seed germination biology of the weedy biennial Alliaria petiolata. Natural Areas Journal 12:191-197.

Beasley JC, Devault TL, Rhodes OEJ. 2007. Home-Range Attributes of Raccoons in a Fragmented Agricultural Region of Northern Indiana. Journal Wildlife Management $71: 844-850$.

Biswas RS and Wagner HH, 2015. Spatial structure in invasive Alliaria petiolata reflects restricted seed dispersal. Biological Invasions. 17:3211-3223.

Blossey B, Nuzzo V, Hinz H, Gerber E. 2001. Developing biological control of Alliaria petiolata (M. Bieb.) Cavara and Grande (Garlic Mustard). Natural Areas Journal 21:357-367.

Bullock JM, Clarke RT. 2000. Long distance seed dispersal by wind: measuring and modelling the tail of the curve. Oecologia 124:506-521. doi: 10.1007/PL00008876

Bullock JM, Shea K, Skarpaas O. 2006. Measuring plant dispersal: An introduction to field methods and experimental design. Plant Ecology 186:217-234. doi: 10.1007/s11258-0069124-5

Burls K, McClaugherty C. 2008. Landscape position influences the distribution of garlic mustard, an invasive species. Northeastern Naturalist 15:541-556. doi: 10.1656/1092-619415.4 .541

Byers DL, Quinn JA. 1998. Demographic variation in Alliaria petiolata (Brassicaceae) in four contrasting habitats. Journal of the Torrey Botanical Society. 125:138-149.

CAB International. 2015. http://www.cabi.org/isc/datasheet/3941, accessed 7 December 2015. Listing of occurrence and invasive status of Alliaria petiolata in USA States by counties and Canadian Provinces. 
690

691

692

693

694

695

696

697

698

699

700

701

702

703

704

705

706

707

708

709

710

711

712

713

714

715

716

717

718

719

720

721

722

Cain ML, Milligan BG, Strand AE. 2000. Long-distance seed dispersal in plant populations. American Journal Botany 87:1217-1227. doi: 10.1016/j.tree.2011.08.009

Cavers PB, Muriel HI, Robert KF. 1979. The biology of Canadian weeds Alliaria petiolata. 35. (M. Bieb) Cavara and Grande. Canadian Journal of Plant Science 59:217-229.

Cipollini, D. Gruner B. 2007. Cyanide in the chemical arsenal of garlic mustard, Alliaria petiolata. Journal of Chemical Ecology 33: 85-94, doi: 10.1007/s10886-006-9205-x

Clark CJ, Poulsen JR, Bolker BM, Connor EF, and Parker VT. 2005. Comparative seed shadows of bird-, monkey-, and wind-dispersed trees. Ecology 86:2684-2694. doi: 10.1890/04-1325

Clark JS, Fastie C, Hurtt G, Jackson ST, Johnson C, King GA, Lewis M, Lynch J, Pacala S, Prentive C, Schupp EW, Webb T, and Wyckoff P. 1998. Reid's paradox of rapid plant migration - Dispersal theory and interpretation of paleoecological records. Bioscience 48:13-24. doi: $10.2307 / 1313224$

Clark JS, Silman M, Kern R, Macklin E, and HilleRisLambers T. 1999. Seed dispersal near and far: patterns across temperate and tropical forests. Ecology 80:1475-1494.

Cousens RD, Dytham C, Law R. 2008. Patterns of dispersal from entire plants. Dispersal Plants. A Population Perspective. Oxford University Press, Oxford, UK, pp 75-110

Cousens RD, Rawlinson AA. 2001. When will plant morphology affect the shape of a seed dispersal "kernel”?. Journal Theoretical Biology 211:229-238. doi: 10.1006/jtbi.2001.2341

Couvreur M, Christiaen B, Verheyen K, Hermy M. 2004. Large herbivores as mobile links between isolated nature reserves through adhesive seed dispersal. Applied Vegetation Science 7:229-236. doi: 10.1111/j.1654-109X.2004.tb00614.x

Couvreur M, Cosyns E, Hermy M, Hoffmann M. 2005. Complementarity of epi- and endozoochory of plant seeds by free ranging donkeys. Ecography (Cop) 28:37-48. doi: 10.1111/j.0906-7590.2005.04159.x

Davis MA, Colehour A, Daney J, Foster E, Macmillen C, Merril E, O’Neil J, Pearson M, Whitney M, Anderson M, Dosch J. 2012. The population dynamics and ecological effects of garlic mustard, Alliaria petiolata, in a Minnesota oak woodland. American Midland Naturalist. 168: 364-374.

Drayton B, Primack RB. 1999. Experimental extinction of garlic mustard (Alliaria petiolata) populations: implications for weed science and conservation biology. Biological Invasions 1:159-167. doi: 10.1023/a:1010017510471

EDDMapS. 2015. Early Detection \& Distribution Mapping System. The University of Georgia Center for Invasive Species and Ecosystem Health. Available online at 
725

726

727

728

729

730

731

732

733

734

735

736

737

738

739

740

741

742

743

744

745

746

747

748

749

750

751

752

753

754

755

https://www.eddmaps.org/distribution/uscounty.cfm?sub=3005/ last accessed December 7, 2015.

Eschtruth AK, Battles JJ. 2009 Assessing the relative importance of disturbance, herbivory, diversity, and propagule pressure in exotic plant invasion. Ecological Monographs 79:265280. doi: 10.1890/08-0221.1

Eschtruth AK, Battles JJ. 2011. The importance of quantifying propagule pressure to understand invasion: an examination of riparian forest invasibility. Ecology 92:1314-1322.

Eschtruth AK, Battles JJ. 2014. Ephemeral disturbances have long-lasting impacts on forest invasion dynamics. Ecology 95:1770-1779. doi: 10.1890/13-1980.1

Evans JA, Landis DA. 2007. Pre-release monitoring of Alliaria petiolata (garlic mustard) invasions and the impacts of extant natural enemies in southern Michigan forests. Biological Control 42:300-307.

Evans JA, Davis AS, Raghu S, Ragavendran A, Landis DA, Schemske DW. 2012. The importance of space, time, and stochasticity to the demography and management of Alliaria petiolata. Ecological Applications 22:1497-1511. doi: 10.1890/11-1291.1

Fischer, Sabine F, Poschlod P, Beinlich B. 1996. Experimental studies on the dispersal of plants and animals on sheep in calcareous grasslands. Journal of Applied Ecology 33:1206-1222.

Gardner HW. 2016. Seed dispersal by roadside mowing. Natural Areas Journal 36: 102-104. doi: $10.3375 / 043.036 .0117$

Gehrt S, Fritzell E. 1998. Resource distribution, female home range dispersion and male spatial interactions: group structure in a solitary carnivore. Animal Behavior 55:1211-27. doi: 10.1006/anbe.1997.0657

Gill RMA, Beardall V. 2001. The impact of deer on woodlands: The effects of browsing and seed dispersal on vegetation structure and composition. Forestry 74:209-218. doi: 10.1093/forestry/74.3.209

Guttal V, Bartumeus F, Hartvigsen G, Nevai AL. 2011. Retention time variability as a mechanism for animal mediated long-distance dispersal. PLoS One. doi: 10.1371/journal.pone.0028447

Heinken T, Schmidt M, Von Oheimb G, Kriebitzsch WU, and Ellenbert H. 2006. Soil seed banks near rubbing trees indicate dispersal of plant species into forests by wild boar. Basic Applied Ecology 7:31-44. doi: 10.1016/j.baae.2005.04.006

Higgins SI, Nathan R, Cain ML. 2003. Are long-distance dispersal events in plants usually caused by nonstandard means of dispersal? Ecology 84:1945-1956. doi: 10.1890/01-0616 
756

757

758

759

760

761

762

763

764

765

766

767

768

769

770

771

772

773

774

775

776

777

778

779

780

781

782

783

784

785

786

787

Hintze C, Heydel F, Hoppe C, Cunze S, Konig A, and Tackenberg O. 2013. D3: The Dispersal and Diaspore Database - Baseline data and statistics on seed dispersal. Perspective in Plant Ecology, Evolution, and Systematics 15:180-192. doi: 10.1016/j.ppees.2013.02.001

Hovstad KA, Borvik S, Ohlson M. 2009. Epizoochorous seed dispersal in relation to seed availabilityan experiment with a red fox dummy. Journal of Vegetation Science 20:455-464.

Johnson JB, Omland KS. 2004. Model selection in ecology and evolution. Trends in Ecology and Evolution 19:101-108. doi: 10.1016/j.tree.2003.10.013

Kalisz S, Spigler RB, Horvitz CC. 2014. In a long-term experimental demography study, excluding ungulates reversed invader's explosive population growth rate and restored natives. PNAS 111: 4501-4506.

Knight TM, Dunn JL, Smith LA, Davis J, Kalisz S. 2009. Deer facilitate invasive plant success in a Pennsylvania forest understory. Natural Areas Journal 29: 110-116.

Kot M, Lewis MA, Den DP van. 1996. Dispersal data and the spread of invading organisms. Ecology 77:2027-2042.

Lankau RA, Nuzzo V, Spyreas G, Davis AS. 2009. Evolutionary limits ameliorate the negative impact of invasive plant. PNAS 106: 15,362-15,367

Lesage L, Crête M, Huot J, Dumont A, and Ouellet JP. 2000. Seasonal home range size and philopatry in two northern white-tailed deer populations. Canadian Journal of Zoology 78:1930-1940. doi: 10.1139/z00-117

Loebach CA, Anderson RC. (2018): Silique length and seed number. figshare. https://doi.org/10.6084/m9.figshare.5890606.v1

Loebach CA, Anderson RC (2017): Garlic mustard seed size. figshare. https://doi.org/10.6084/m9.figshare.5664880

Mansouri H. 1999. Aligned rank transform tests in linear models. Journal of Statistical Planning and Inference 79:141-155. doi: 10.1016/S0378-3758(98)00229-8

Mansouri H, Paige RL, Surles JG. 2004. Aligned rank transform techniques for analysis of variance and multiple comparisons. Communication in Statistics - Theory and Methods 33:2217-2232. doi: 10.1081/STA-200026599

Meekins JF, Mccarthy BC. 1999. Competitive ability of Alliaria petiolata (Garlic Mustard, Brassicaceae), an invasive, nonindigenous forest herb. International Journal of Plant Sciences 160:743-752. 
788

789

790

791

792

793

794

795

796

797

798

799

800

801

802

803

804

805

806

807

808

809

810

811

812

813

814 815

816

817

818

Myers JA., Vellend M, Gardescu S. 2004. Seed dispersal by white-tailed deer: Implications for long-distance dispersal, invasion, and migration of plants in eastern North America. Oecologia 139:35-44. doi: 10.1007/s00442-003-1474-2

Mullarkey AA, Byers DL, Anderson R. 2013. Inbreeding depression and partitioning of genetic load in the invasive biennial Alliaria petiolata (Brassicaceae). American Journal of Botany 100:509-518. doi: 10.3732/ajb.1200403

Nathan R. 2006. Long-distance dispersal of plants. Science 313:786-788. doi: 10.1126/science. 1124975

Nathan R, Klein E, Robledo-Arnuncio JJ, Revilla E. 2012. Dispersal kernels: review. In: J C, Baguette M, Benton T, Bullock J (eds) Dispersal Ecology Evolution. Oxford University Press, pp 187-210

Nathan R, Muller-Landau HC. 2000. Spatial patterns of seed dispersal, their determinants and consequences for recruitment. Trends in Ecology and Evolution. 15:278-285.

Nathan R, Schurr FM, Spiegel O, Steinitz O, Trakhtenbrot A, Tsoar A. 2008. Mechanisms of long-distance seed dispersal. Trends in Ecology and Evolution 23:638-647. doi:

10.1016/j.tree.2008.08.003

Nuzzo V. 1993. Current and historic distribution of garlic mustard (Alliaria petiolata) in Illinois. Michigan Botanist 34:23-33.

Nuzzo V. 1999. Invasion pattern of the herb garlic mustard (Alliaria petiolata) in high quality forests. Biological Invasions 1:169-179. doi: 10.1023/a:1010009514048

Nuzzo VA, Marerz JC, Blossey B. 2009. Earthworm invasion as the driving force behind plant invasion and community change in northeastern North American forests. Conservation Biology 23: 966-974.

Pablos I de, Peco B. 2007. Diaspore morphology and the potential for attachment to animal coats in Mediterranean species: an experiment with sheep and cattle coats. Seed Science Research 17:109-114.

Peart DR. 1985. The quantitative representation of seed and pollen dispersal. Ecology 66:10811083.

Pergl J, Müllerová J, Perglová I, Herbe T, and Pysek P. 2011. The role of long-distance seed dispersal in the local population dynamics of an invasive plant species. Diversity and Distributions 17:725-738. doi: 10.1111/j.1472-4642.2011.00771.x 
819

Philips-Mao L, Larson DL, Jordan NR. 2014. Effects of native herbs and light on garlic mustard (Alliaria petiolata) invasion. Invasive Plant Science and Management 7:257-268.

Richter SJ. 1999. Nearly exact tests in factorial experiments using the aligned rank transform. Journal of Applied Statistics 26:203-217. doi: 10.1080/02664769922548

Roberts KJ, Anderson RC. 2001. Effect of garlic mustard [Alliaria petiolata (Beib. Cavara \& Grande)] extracts on plants and arbuscular mycorrhizal (AM) fungi. American Midland Naturalist 146:146-152. doi: 10.1674/0003-0031(2001)146[0146:EOGMAP]2.0.CO;2

Rodgers VL, Stinson KA, and Finzi AC. 2008. Ready or not, garlic mustard is moving in: Alliaria petiolata as a member of eastern North American forests. BioScience 58: 426436.

Römermann C, Tackenberg O, Poschlod P. 2005. How to predict attachment potential of seeds to sheep and cattle coat from simple morphological seed traits. Oikos 110:219-230. doi: 10.1111/j.0030-1299.2005.13911.x

Ruxton GD. 2006. The unequal variance t-test is an underused alternative to Student's t-test and the Mann-Whitney U test. Behavioral Ecology 17:688-690. doi: 10.1093/beheco/ark016

SAS Institute. 2012. SAS User's Guide, Version 9.3. SAS Institute Inc., Cary, NC, USA

Schulze KA, Buchwald R, Heinken T. 2014. Epizoochory via the hooves - the European bison (Bison bonasus L.) as a dispersal agent of seeds in an open-forest-mosaic. Tuexenia 34:131-143. doi: 10.14471/2014.34.016

Schurr FM, Steinitz O, Nathan R. 2008. Plant fecundity and seed dispersal in spatially heterogeneous environments: Models, mechanisms and estimation. Journal of Ecology 96:628-641. doi: 10.1111/j.1365-2745.2008.01371.x

Skarpaas O, Shea K, Bullock JM. 2005. Optimizing dispersal study design by Monte Carlo simulation. Journal Applied Ecology 42:731-739. doi: 10.1111/j.1365-2664.2005.01056.x

Suarez AV, Holway DA, Case TJ. 2001. Patterns of spread in biological invasions dominated by long-distance jump dispersal: Insights from Argentine ants. PNAS 98:1095-1100. doi: 10.1073/pnas.98.3.1095

Susko DJ, Lovett-Doust L. 2000. Patterns of seed mass variation and their effects on seedling traits in Alliaria petiolata (Brassicaceae). American Journal of Botany 87:56-66.

Tackenberg O, Römermann C, Thompson K, Poschlod P. 2006. What does diaspore morphology tell us about external animal dispersal? Evidence from standardized experiments measuring seed retention on animal-coats. Basic and Applied Ecology 7:45-58. doi: 10.1016/j.baae.2005.05.001 
852 Theoharides KA, Dukes JS. 2007. Plant invasion across space and time: factors affecting

853

854

855

856

857

858

859

860

861

862

863

864

865

866

867

868

869

870

871

872

873

874

875

876

877

878

879

880 nonindigenous species success during four stages of invasion. New Phytologist 176:256273.

Tutin T, Burges NA, Chater AO, Edmondson JR, Heywood VH, Moore DM, Valentine DH, Walters SM, Webb DA. 1964. Flora Europaea Vol. 1. Cambridge Universtiy Press

USDA NRCS. 2014. The PLANTS Database. In: USDA Natl. Plant Cent. http://plants.usda.gov/core/profile?symbol=alpe4.

Van Riper LC, Becker RL, Skinner LC. 2010. Population Biology of Garlic Mustard (Alliaria petiolata) in Minnesota Hardwood Forests. Invasive Plant Science and Management 3:4859.

Venable DL, Flores-Martinez A, Muller-Landau HC, Barron-Gafford G, and Becerra JX. 2008. Seed dispersal of desert annuals. Ecology 89:2218-2227. doi: 10.1890/07-0386.1

Welk E, Schubert K, Hoffmann MH. 2002. Present and potential distribution of invasive garlic mustard (Alliaria petiolata) in North America. Diversity and Distributions 8:219-233.

Will H, Maussner S, Tackenberg O. 2007. Experimental studies of diaspore attachment to animal coats: Predicting epizoochorous dispersal potential. Oecologia 153:331-339. doi: 10.1007/s00442-007-0731-1

Wilson MF. 1993. Dispersal mode, seed shadows, and colonization patterns. Vegetatio 107108:261-280.

Wobbrock JO, Findlater L, Gergle D, Higgins JJ. 2011. The aligned rank transform for nonparametric factorial analyses using only ANOVA procedures. CHI '11 Conference on Human Factors in Computer Systems 143-146. doi: 10.1145/1978942.1978963

Wolfram Alpha LLC. 2009. Wolfram|Alpha Double Integral Calculator http://www.wolframalpha.com/widgets/view.jsp?id=f5f3cbf14f4f5d6d2085bf2d0fb76e8a (access Jan 20, 2015)

Yang X, Baskin JM, Baskin CC, Huang Z. 2012. More than just a coating: Ecological importance, taxonomic occurrence and phylogenetic relationships of seed coat mucilage. Perspectives in Plant Ecology, Evolution, and Systematics 14:434-442. doi: 10.1016/j.ppees.2012.09.002 


\section{Figure 1 (on next page)}

A diagram of the seed trap study experiment design.

Seed traps were place at distances $0.25,0.5,0.75,1.25,2.25$, and 3.25 meters from the seed point source and at every 45 azimuth degrees. 

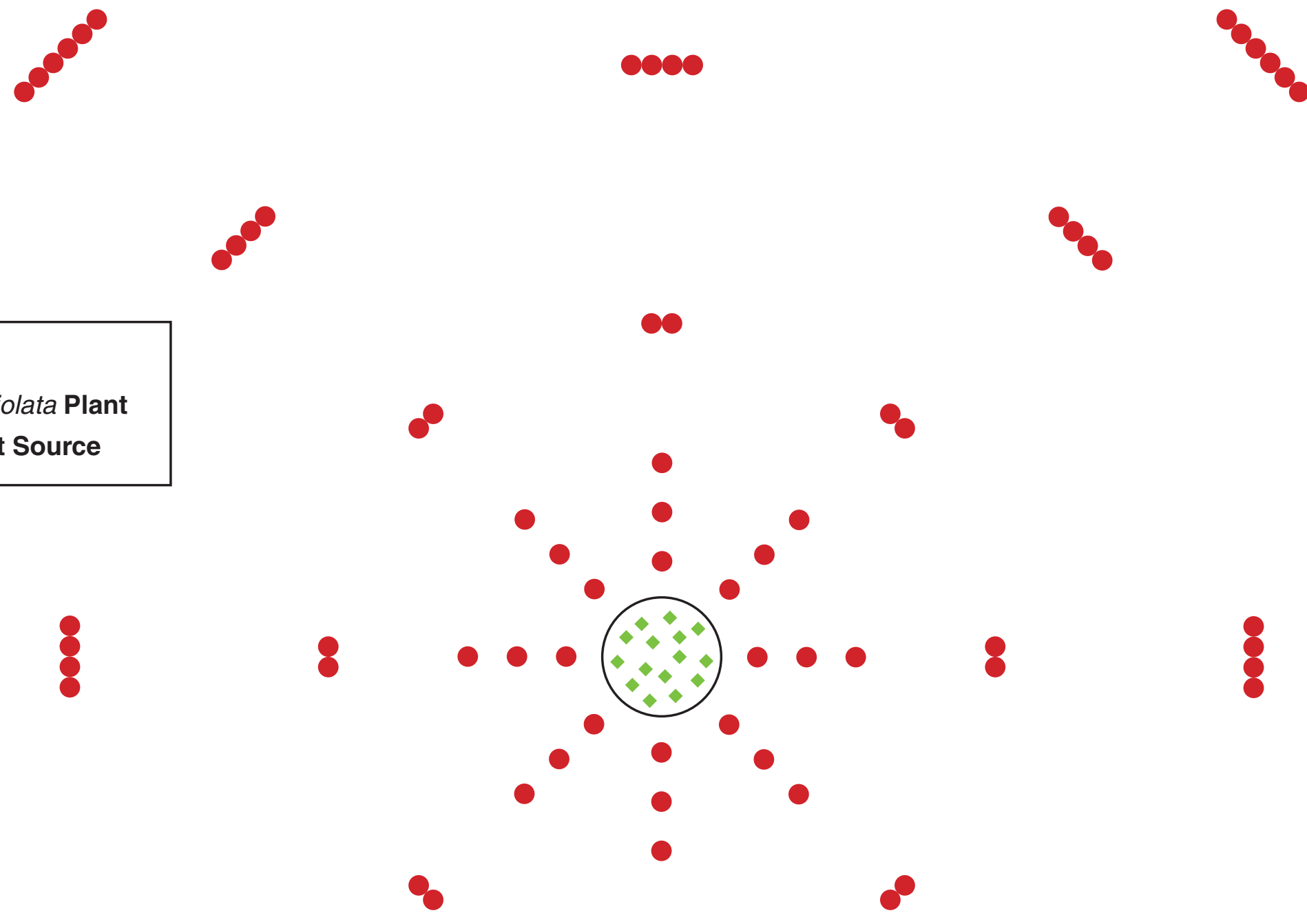

$\infty$

- Seed Trap

$\checkmark$ Alliaria petiolata Plant

$\bigcirc$ Seed Point Source

8

8

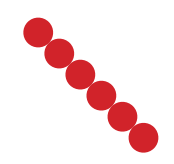

$\$ 00000$

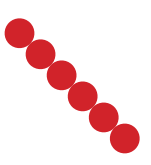

8

8

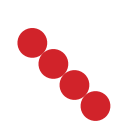



$\infty$

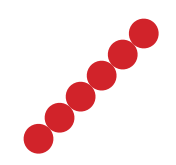


Figure 2 (on next page)

The density pdf $(g(r))$ of the $2 \mathrm{Dt}$ function.

The $g(r)$ describes the probability of a seed landing into an infinitely small area at a specific distance from the point source. 


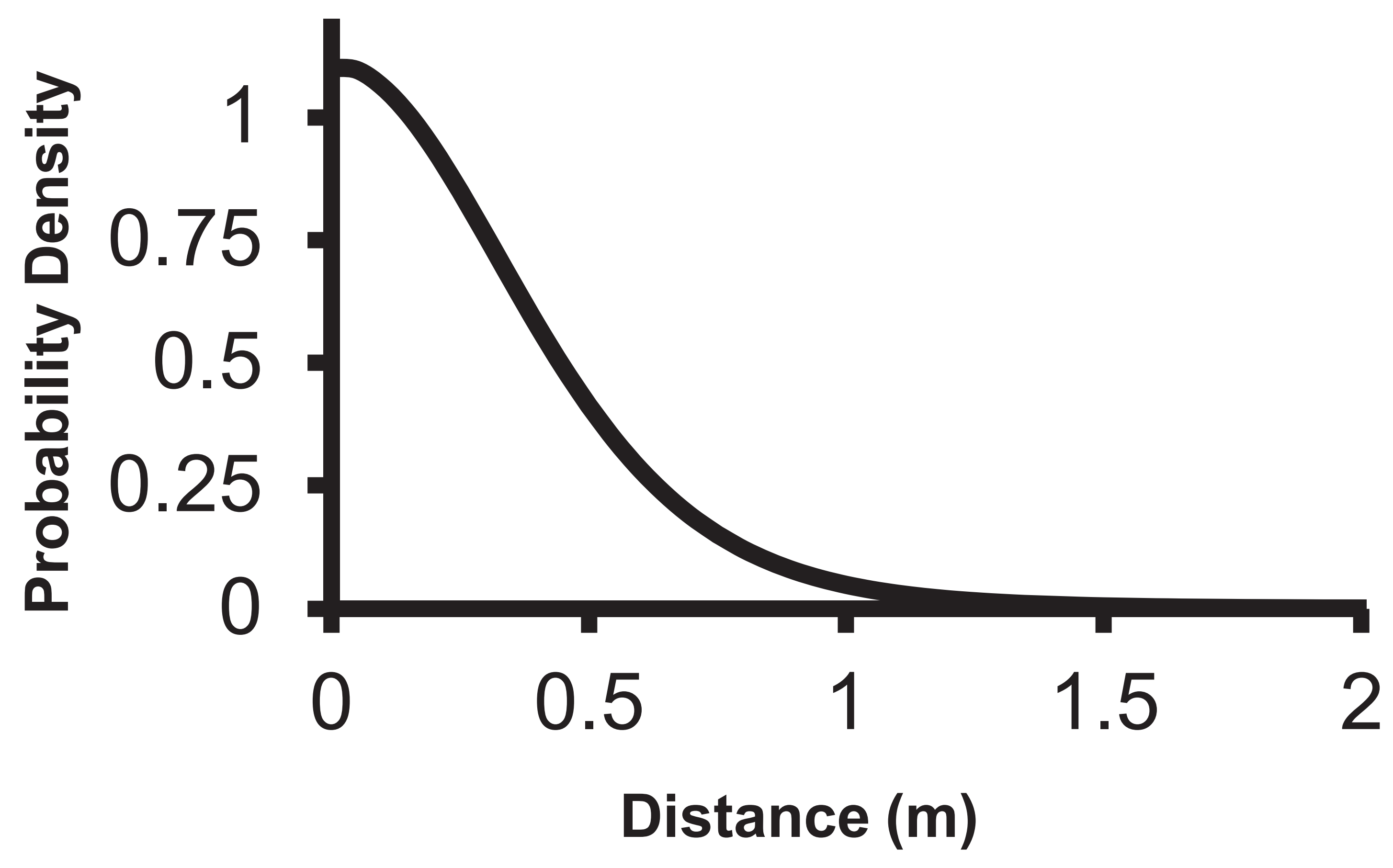


Figure 3 (on next page)

The predicted seed count per trap (solid line) $\pm 95 \%$ confidence intervals (dashed lines) for 2Dt function for each point source, a) Point Source 1, b) Point Source 2, and c) Point Source 3.

Each of the point sources was plotted separately and the black diamonds are the seed counts from the seed traps. 

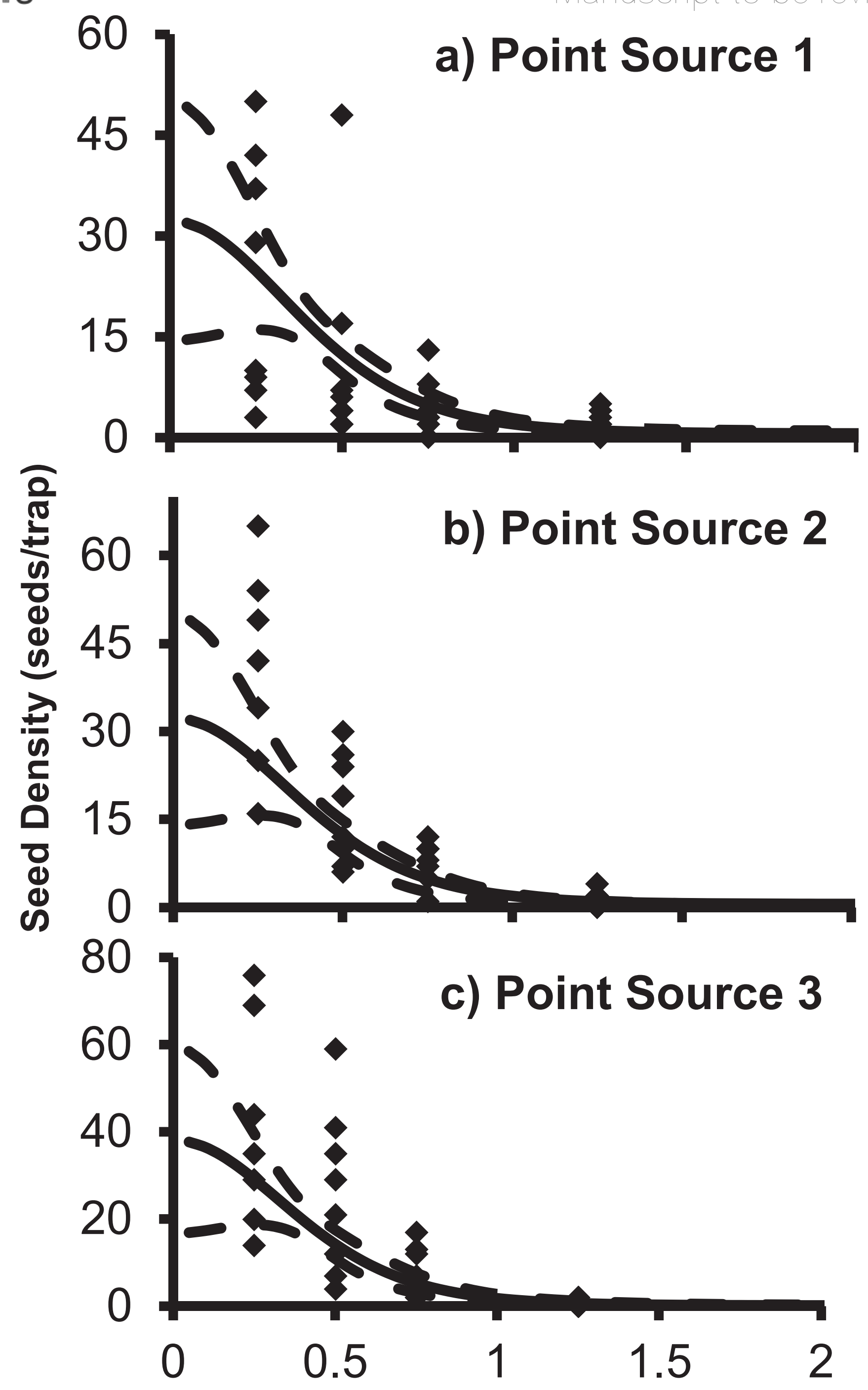

Distance (m) 
Figure 4(on next page)

The change in predicted seed density as distance from the parent plant increases as predicted by the negative exponential function from Eschtruth and Battles (2009) and the $2 \mathrm{Dt} g(r)$ function.

The fecundity of the parent plant was set to 156 seeds as this was the value used by Eschtruth and Battles (2009). Beginning at 0.50 meters, the negative exponential overestimates the dispersed seed density compared to the $2 \mathrm{Dt} g(r)$ kernel. 


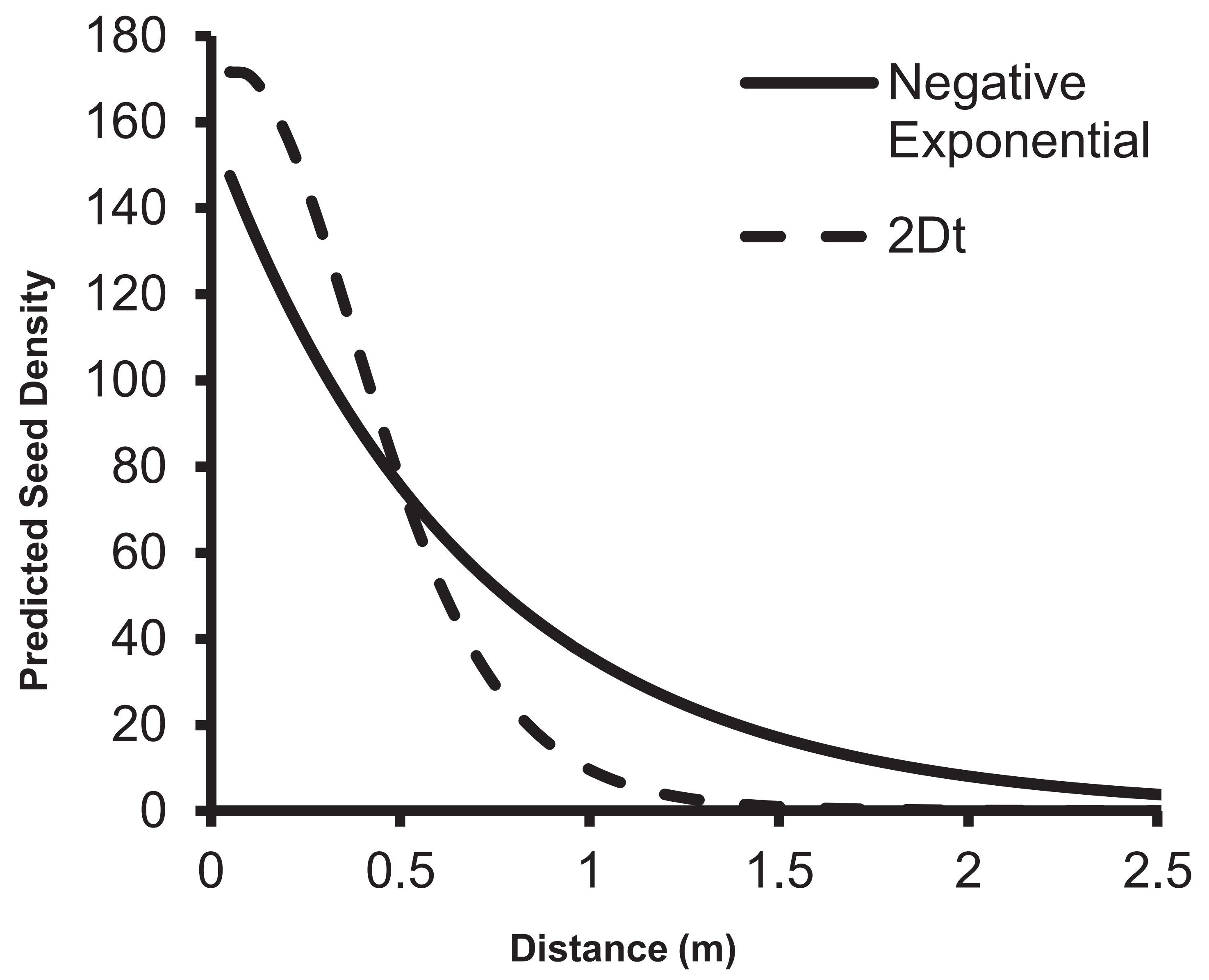


Figure $\mathbf{5}$ (on next page)

The distance pdf $(f(r))$ of the 2Dt function.

The $f(r)$ describes the probability of a seed dispersing to a specific distance from the point source. 


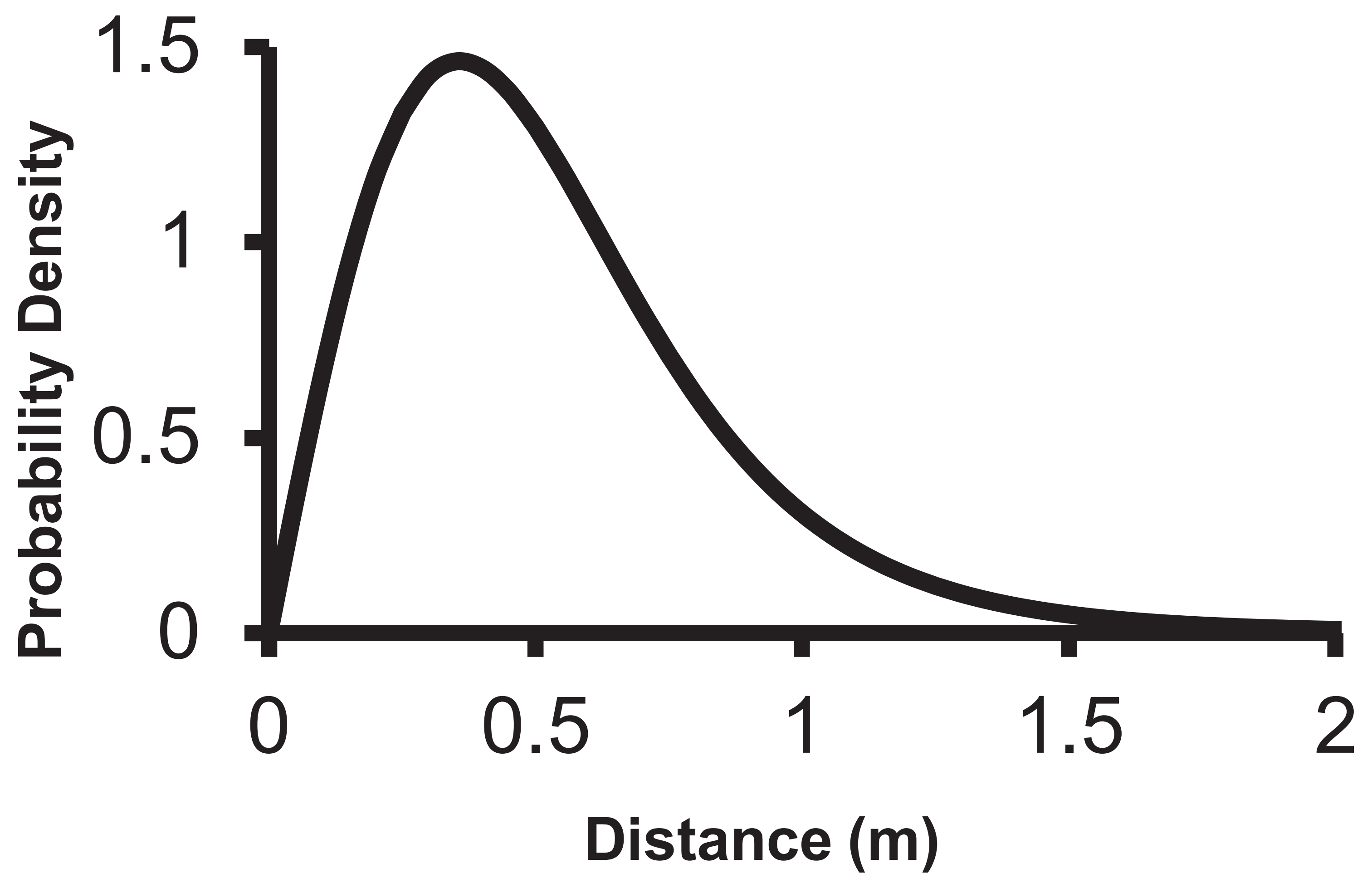


Figure 6 (on next page)

The back transformed mean number $( \pm 95 \% \mathrm{Cl})$ of $A$. petiolata seedlings counted in the germination trays of the two treatments.

The confidence intervals are not symmetrical because of the back transformation. The MIT trays $(p<0.0001)$ had significantly more seedlings than the control trays. 


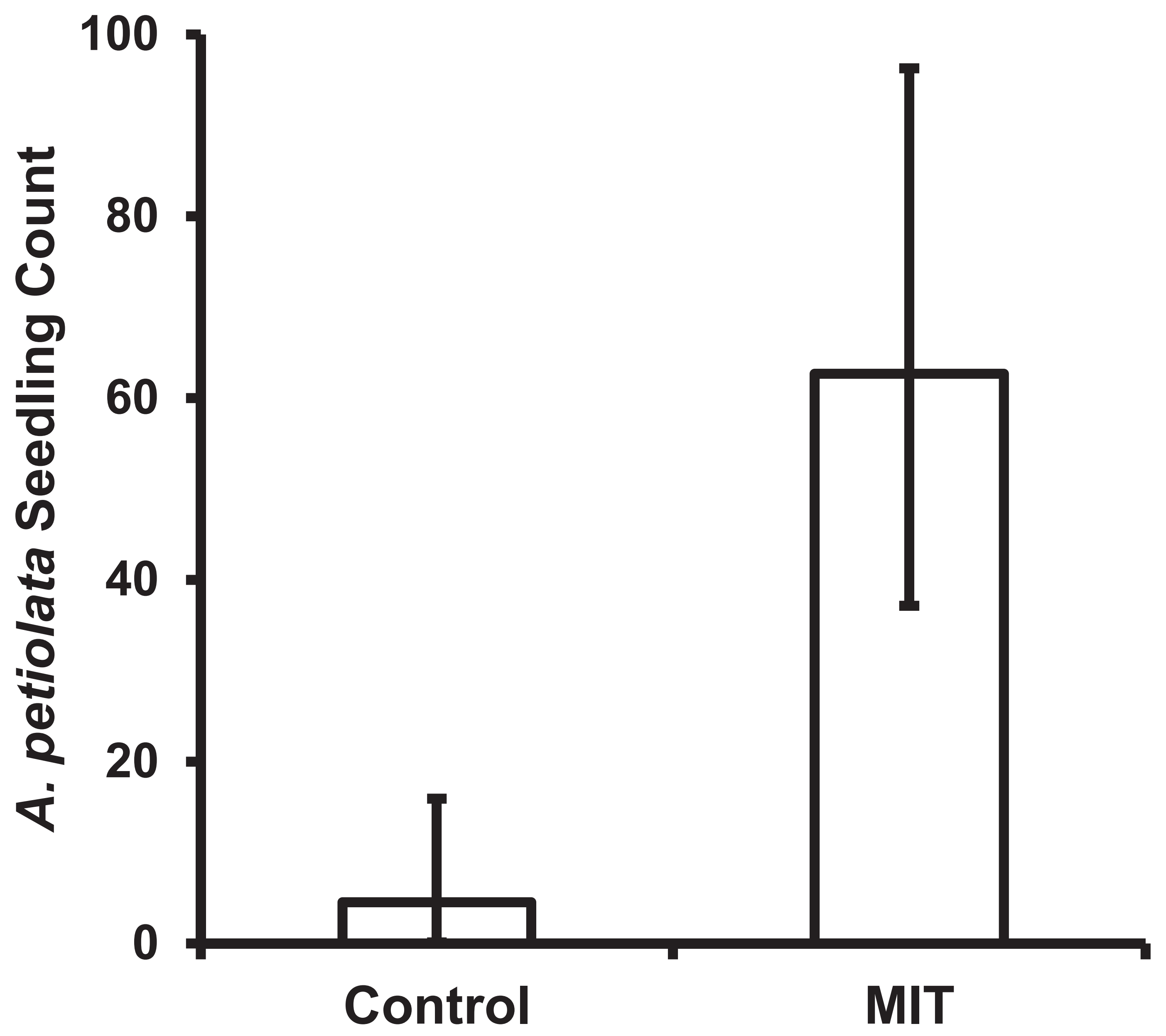


Figure 7 (on next page)

The mean $( \pm S D)$ AtP values for each treatment combination for the a) deer and $c$ ) raccoon pelts and the box and whisker plot of results of the Tukey follow test on the ART values of the interaction between seed and fur condition for the b) deer and d) racoon

Th Significant differences are marked by different letters. 

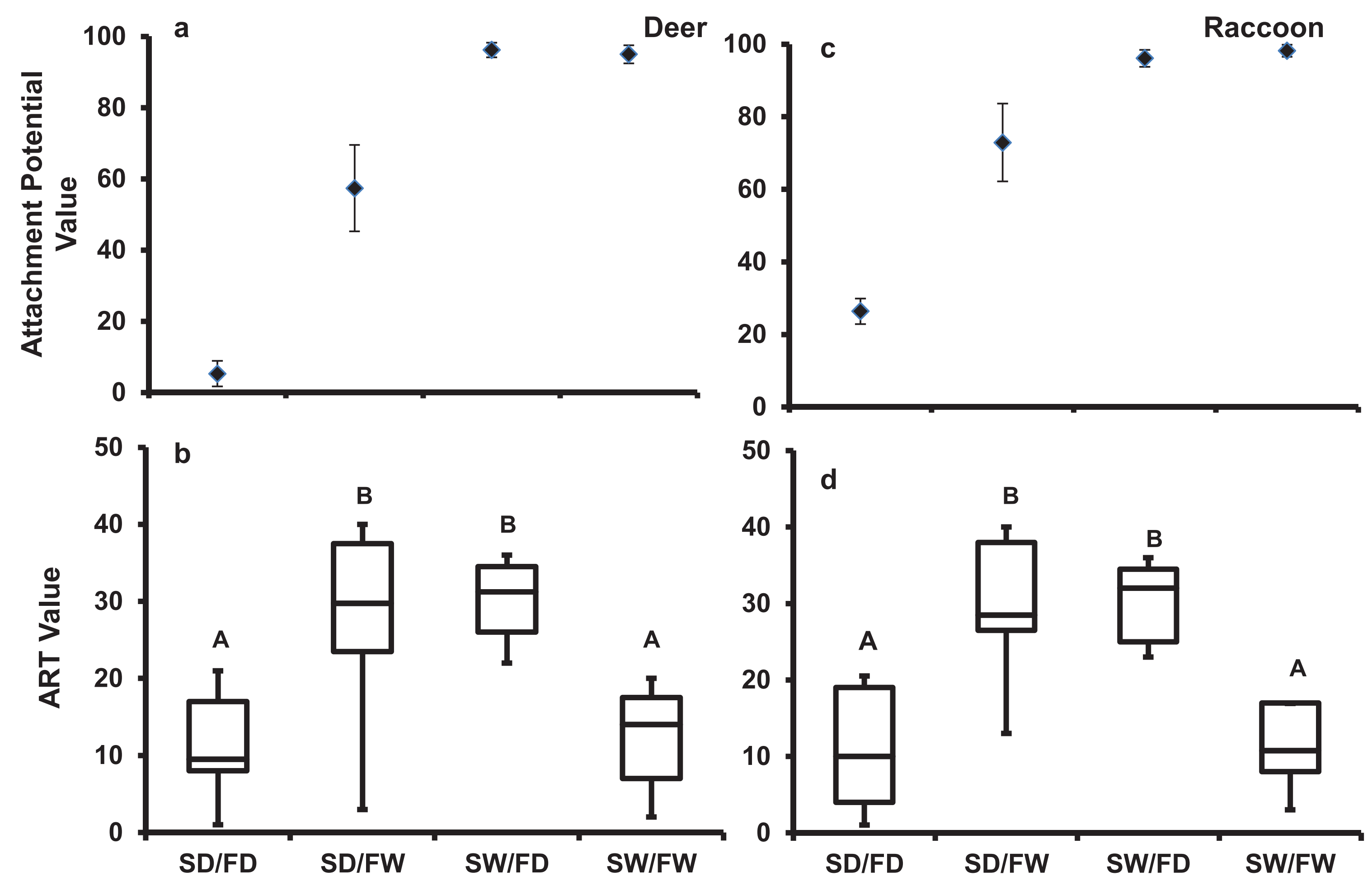
Figure 8 (on next page)

The mean $( \pm 95 \% \mathrm{Cl})$ retention potential for the deer and raccoon pelts.

The retention potential was significantly higher when the pelt was wet for both the deer and raccoon pelts. The $95 \%$ confidence intervals did not overlap with zero for any treatment. 


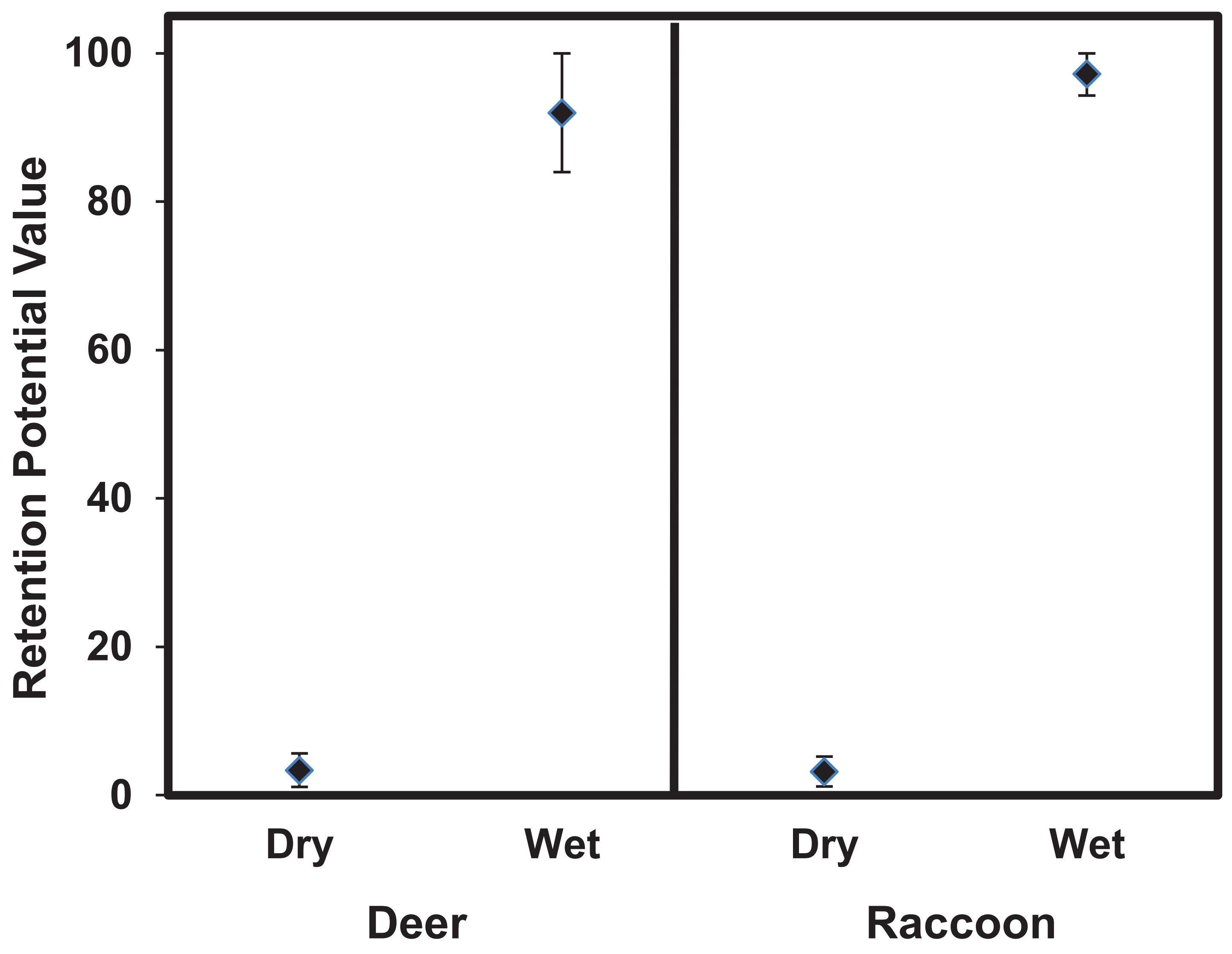




\section{Table $\mathbf{1}$ (on next page)}

The eight $g(r)$ dispersal functions as described in Nathan et al. (2012) that were fitted to the seed trap data.

The parameter $a$ is a shape parameter and $b$ is a scale parameter which determines the relative weight of long distance dispersal events, and $r$ is the distance from the center of the point source. 


\begin{tabular}{cl}
\hline Function & $\mathbf{g}(\boldsymbol{r})$ \\
\hline Negative Exponential & $\frac{1}{2 \pi a^{2}} \exp \left(-\frac{r}{a}\right)$ \\
Log Normal & $\frac{1}{2 \pi^{3 / 2} b r^{2}} \exp \left(-\frac{\log \left(\frac{r}{a}\right)^{2}}{2 b^{2}}\right)$ \\
2Dt & $\frac{(b-1)}{\pi a^{2}}\left(1+\frac{r^{2}}{a^{2}}\right)-b$ \\
Weibull & $\frac{b}{2 \pi \mathrm{a} 2} r^{\mathrm{b}-2} \exp \left(\frac{r^{2}}{a^{b}}\right)$ \\
Gaussian & $\frac{1}{\pi a^{2}} \exp \left(\frac{r^{2}}{a^{2}}\right)$ \\
Logistic & $\frac{b}{2 \pi \mathrm{a} 2 \Gamma(2 / b) \Gamma(1-2 / \mathrm{b})} \exp \left(1+\frac{r^{b}}{a^{b}}\right)-1$ \\
Exponential Power & $\frac{b}{2 \pi a^{2} \Gamma(2 / \mathrm{b})} \exp \left(-\frac{r^{b}}{a^{b}}\right)$ \\
(Inverse) Power-Law & $\frac{(b-2)(b-1)}{2 \pi a^{2}}\left(1+\frac{r}{a}\right)-b$
\end{tabular}




\section{Table 2 (on next page)}

The average number of seeds $( \pm \mathrm{SE})$ captured in a single trap at each distance for all three point sources. 


\begin{tabular}{clll}
\hline D (m) & Source 1 & Source 2 & Source 3 \\
\hline 0.25 & $23.4( \pm 6.47)$ & $49.6( \pm 10.51)$ & $39.7( \pm 11.32)$ \\
0.5 & $11.2( \pm 5.52)$ & $16.7( \pm 3.27)$ & $26.0( \pm 6.64)$ \\
0.75 & $4.8( \pm 1.44)$ & $7.8( \pm 1.24)$ & $7.9(1.96)$ \\
1.25 & $1.6( \pm 0.43)$ & $1.3(0.36)$ & $0.46( \pm 0.210)$ \\
2.25 & $0.84( \pm 0.147)$ & $0.22(0.088)$ & $0.16( \pm 0.066)$ \\
3.25 & $0.46( \pm 0.104)$ & $0.19(0.063)$ & $0.12( \pm 0.054)$
\end{tabular}




\section{Table 3(on next page)}

The parameter estimates and their standard errors of the 2Dt function.

Parameter values were based on the pooled data from the three plots. Standard error values are approximate due to the method SAS uses to calculate them. P-values are for alpha $<0.05$ and hypothesis of parameter $=0$. 


\begin{tabular}{ccccc}
\hline Parameter & Estimate & St. Err & DF & p-value \\
\hline$A$ & 1.0561 & 0.3427 & 2 & 0.0911 \\
$B$ & 4.8795 & 2.1794 & 2 & 0.1545 \\
$U$ & 0.1474 & 0.1282 & 2 & 0.3692 \\
$K$ & 0.6493 & 0.1062 & 2 & 0.0257
\end{tabular}

1 
Table 4 (on next page)

The photo counts for each animal species that visited the treatments for both study years combined.

Turkeys were only observed in 2014. Raccoon was the only animal observed at all seven $A$. petiolata patches. 


\begin{tabular}{ccc}
\hline Animal & MIT & Control \\
\hline Raccoon & 720 & 46 \\
Turkey & 147 & 0 \\
Deer & 32 & 0 \\
Squirrel & 2 & 2 \\
Nuthatch & 9 & 0 \\
Blue Jay & 3 & 0 \\
Chipmunk & 10 & 2 \\
Mouse & 4 & 0 \\
Cardinal & 1 & 0 \\
Mourning Dove & 3 & 0 \\
Woodchuck & 1 & 0
\end{tabular}

1 


\section{Table 5 (on next page)}

The distance $(\mathrm{m})$ between the north and south blocks and the east and west blocks for each $A$. petiolata patch and the average density of second-year plants per $1 \mathrm{~m}^{2}$.

Patches 1-3 and 4-7 were used in 2013 and 2014, respectively. 


\begin{tabular}{cccc}
\hline Patch & $\mathrm{N}$ to S $(\mathrm{m})$ & $\mathrm{E}$ to W $(\mathrm{m})$ & Density $\left(\mathrm{m}^{2}\right)$ \\
\hline 1 & 10 & 16 & 141 \\
2 & 9.4 & 9.4 & 237 \\
3 & 22 & 11.8 & 258 \\
4 & 11.3 & 14.5 & 41 \\
5 & 13 & 11.3 & 51 \\
6 & 18.3 & 13.3 & 24 \\
7 & 20 & 17 & 60
\end{tabular}

